\title{
GRABADOS RUPESTRES EN EL SUR DE LA PROVINCIA DE LUGO
}

\section{Rock art in the south of the province of Lugo}

\author{
Begoña González Aguiar ${ }^{1}$
}

Recibido el 14 de mayo de 2012. Aceptado el 8 de agosto de 2012

Resumen. En este artículo se plasman los resultados obtenidos tras el estudio de cincuenta estaciones rupestres ubicadas, todas ellas, en el sur de la provincia de Lugo. En un primer momento se llevaron a cabo labores de prospección y análisis de las estaciones, para su posterior estudio descriptivo, simbólico y espacial. Tales trabajos confirman la existencia de representaciones en una "zona marginada" como es la provincia de Lugo, frente a Pontevedra y A Coruña. Además, se han catalogado veinte estaciones inéditas, desconocidas hasta la fecha.

Palabras clave: Arte Rupestre, Petroglifos Gallegos, Grabados, Lugo, Paisaje, Simbolismo.

Abstract. This article embodies the results obtained from the study of fifty rock art sites locales in the south of the province of Lugo. First, we explored the sides and analyzing them for description, symbolism and places of context. The investigation confirms the existence of representations in a "marginal area", the province of Lugo, excluded by other investigators of Pontevedra and A Coruña. Also, we have been able to catalog twenty stations unpublished and unknown to date.

Key words: Rock Art, Galician Petroglyphs, Engraved, Lugo, Landscape, Simbolism.

\section{PRESENTACIÓN}

El estudio del arte rupestre gallego se ha centrado, desde las primeras investigaciones, en el ámbito de las Rías Baixas, referente imprescindible en el Noroeste peninsular. El gran número y variedad de las estaciones han sido los principales motivos para que la mayoría de los investigadores dirijan sus estudios hacia esta área, dejando al margen el resto de hallazgos, cada vez menos aislados, en las restantes provincias gallegas.

A continuación, alejándonos de esa tendencia discriminatoria, analizaremos cincuenta grabados rupestres de la provincia de Lugo, concretamente los situados en la zona sur, mediante la realización de una minuciosa catalogación en dicha zona y su posterior estudio en gabinete plasmado brevemente en estas páginas.

\subsection{Comarcas}

El trabajo de investigación se centra en las comarcas de Chantada, Terras de Lemos y Quiroga, todas ellas deli- mitadas por los ríos Miño y Sil, y sus principales afluentes: Búbal, Cabe y Lor. Será en las proximidades de sus vertientes fluviales donde se ubiquen el mayor número de grabados rupestres de la zona.

La comarca de Chantada, localizada al Oeste de la provincia de Lugo, se ve condicionada por la Dorsal Meridiana Gallega y el río Miño. Limita al Norte con A Ulloa y Portomarín (Lugo), al Oeste con Lalín (Pontevedra), al Sur con A Peroxa (Ourense) y al Este con el río Miño, que a su vez la separa de la comarca monfortina. Su extensión es de 462,2 $\mathrm{km}^{2}$, divididos en tres ayuntamientos: Carballedo, Chantada y Taboada. Presenta clima oceánico, pero dentro de la variedad interior de la meseta lucense, junto a un matiz mediteráneo propio de las riberas de río Miño.

Morfológicamente la comarca se estructura en tres unidades bien diferenciadas: al Este la ribera del Miño, en el centro una amplia superficie de aplanamiento situada y al Oeste las Sierras de 0 Faro y 0 Farelo. Ambas sierras se originaron como consecuencia de los movimientos tectónicos

(1) Departamento de Prehistoria y Arqueología. UNED. Doctoranda. begonzalezaguiar@gmail.com 


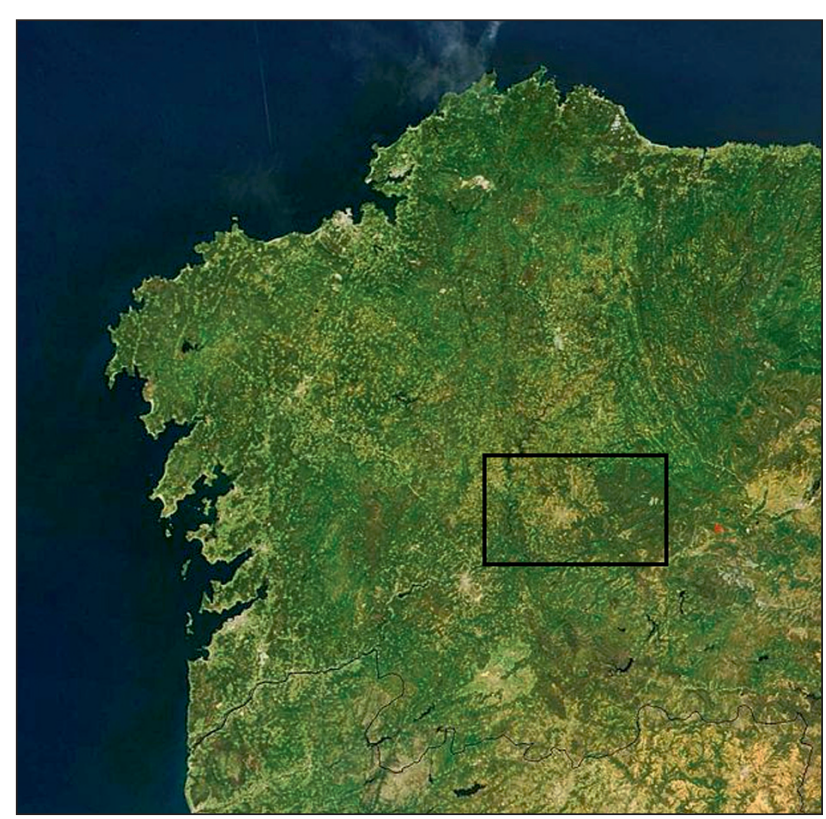

- Figura 1. Mapa general de Galicia con la zona de estudio enmarcada. Nasa Satellite.

acontecidos en la primera mitad del Terciario, debido a fracturas y tensiones producidas por la orogénesis alpina. Las pendientes del río Miño son fuertes y de origen tectónico, las cuales se corresponden con líneas de fractura y fallas sobre las que posteriormente circulan los lechos fluviales (Rodríguez González 2005b: 21-22). Su mayor altitud está en 0 Marco, pico situado en el Monte Faro, a 1187 metros de altura. Existe una gran diversidad litológica dominada por los materiales graníticos. Además, en el espacio central de la comarca hallamos una superficie de erosión englobada dentro del dominio esquistoso de la Galicia central y occidental. Sus materiales han sido arrastrados por la erosión y elevados mediante la acción bascular de bloques originados por el movimiento alpino, situados a una altitud que oscila entre los 600 y 700 metros (Rodríguez González 2005b: 22).

La comarca de Terras de Lemos se sitúa en el borde meridional de la meseta de Lugo, donde coincide con una sucesión de superficies de aplanamiento a distintos niveles, alteradas por los cañones de los ríos Sil, Miño y Cabe, junto a los contrafuertes occidentales de la sierra de 0 Courel. Limita al Norte con Sarria (Lugo), al Oeste con el río Miño que la separa de Chantada (Lugo), al Sur con el río Sil que la aleja de Ourense y, finalmente, al Este con Quiroga (Lugo). Su extensión es de 940,4 km², en los que se distribuyen los concejos de Bóveda, Monforte de Lemos, Pantón, A Pobra de Brollón, 0 Saviñao y Sober. El clima es variado debido a su relieve, pues posee cuatro tipos derivados del oceánico: continental, mediterráneo, de montaña y de transición.

Morfológicamente encontramos grandes unidades de relieve distribuidas por los cañones de los ríos Miño y Sil; las superficies de aplanamiento en la zona occidental; la zona oriental los contrafuertes de la sierra de 0 Courel; y la depresión tectónica de Lemos en el centro de la comarca. Esta última, de gran amplitud, se vincula al período Terciario en las altitudes que oscilan entre los 300 y los 400 metros destacando, en contraposición, los cerros aislados, resultado de la erosión diferencial. Su mayor altitud se localiza en los altos da Serna y Neveira, a 1135 metros y 1142 metros, respectivamente. Litológicamente existe una yuxtaposición de materiales metamórficos, graníticos y sedimentarios. Los primeros predominan en el extremo suroeste, borde septentrional y en la mitad oriental de ese territorio; los segundos coinciden con una franja con orientación sureste-noroeste, que bordea por el sur y oeste la depresión de Lemos. Finalmente, la zona central coincidente con el fondo de la depresión está cubierta de materiales sedimentarios cuaternarios (Rodríguez González 2005a: 21-25).

La comarca de Quiroga se localiza al Sureste de la provincia de Lugo, frontera oriental entre Galicia y León. Limita al Norte con Os Ancares (Lugo), al Oeste con Sarria y Terra de Lemos (Lugo), al Sur con Ourense y al Este con León. Su extensión es de 578,0 km², repartidos en los ayuntamientos de Folgoso do Caurel, Quiroga y Ribas de Sil. El clima es mediteráneo húmedo y, dentro del las variables gallegas, pertenece al tipo de las sierras orientales. Esta uniformidad climática sólo se ve alterada en la zona sur, por las riberas del Sil, donde encontramos pequeños matices mediterráneos.

La extensa cuenca fluvial del río Quiroga y Sil, junto a la prolongación de la Sierra de 0 Caurel otorgan a esta comarca de un entorno único de fauna y flora. Sus mayores elevaciones son Piapáxaro con 1.647 metros, Montouto con 1.546 metros y Lago Grande con 1.246 metros. En la zona norte y oeste se localiza el área de montaña, labrada, la septentrional, por duros materiales en los que encaja el río Lor. Por el contrario, en la zona meridional de la comarca se sitúa una cuenca hundida entre las alineaciones del Caurel y las situadas al sur, de forma irregular. El valle está tapizado de materiales del cuaternario, arcillas, arenas, etc. El sustrato litológico es diferente a los anteriores, compuesto principalmente por cuarzo, pizarra y roca calcárea. La laguna de Lucenza, situada a 1420 metros de altura, y al Valle de A Seara, ambos en Folgoso do Caurel, son de origen glaciar.

\section{HISTORIA DE LA INVESTIGACIÓN}

Este apartado es una breve introducción sobre la evolución histórica que han sufrido las diferentes teorias sobre el arte rupestre gallego desde mediados del siglo XVIII hasta la actualidad.

La primera mención conocida data del año 1750. Fray Martín Sarmiento en su obra Viaje a Galicia señala varios grabados cruciformes hallados en rocas, junto a otras representaciones, en el ayuntamiento de Cotobade. Un siglo más tarde, Manuel Murguía en Historia de Galicia menciona 
varios grabados denominados celtas, vinculados al mundo megalítico y castrexo. El ilustre historiador, de corriente nacionalista, propicia la popularidad de los petroglifos, pero también se vale de ellos para defender el origen celta de Galicia, Bretaña, Irlanda y Escocia. Autores como Luis de la Riega o Barros Sivelo (1875: 74-76) ven una posible relación entre estos grabados y los signos astronómicos vinculados a algún tipo de ritual druídico. En esta época nos encontramos con escritos de poca calidad y muy ideológicos, enfocados a enfatizar el pasado celta glorioso de nuestros antepasados gallegos. Por otro lado, García de la Riega, alejado del ambiente proceltista, afirma que cronológicamente pertenecen al Neolítico, concretamente una escritura producida por kimros, opinión ya defendida por Martínez Salazar (Peña Santos 1998: 9).

No será hasta comienzos del siglo XX cuando se gesten obras de mayor rigor sobre el arte rupestre gallego. En esta época se crea la Sociedad Arqueológica de Pontevedra que promoverá el estudio e inventario de los complejos rupestres de la provincia. Enrique Campo Sobrino será el encargado de ilustrar gráficamente los yacimientos. En los años 20, las estaciones galaicas ya son conocidas internacionalmente; esto propicia que historiadores foráneos se interesen por nuestro patrimonio, como fue el caso de Hugo Obermaier, quien realiza la primera clasificación de estilos diferenciando el Grupo Antiguo, integrado por herraduras, cruces, ídolos..., originados en el arte esquemático, y el Grupo Reciente, compuesto por combinaciones circulares y zoomorfos, ubicados cronológicamente en la Edad de Bronce. Obermaier será un autor muy influyente en la época, Florentino López Cuevillas y Fermín Bouza-Brey seguirán sus pasos, pero sin aportar novedades a la investigación; prueba de ello es la amplia clasificación tipológica de los grabados rupestres que plantean: alfabetiformes, antropomorfos, espirales, combinaciones circulares, zoomorfos, soliformes, óvalos, esvásticas y serpentiformes (López Cuevillas y Bouza Brey 1929: 48-58). De la mano de Sobrino Buhigas, sucesor de Enrique Campo Sobrino, nos llega el primer monográfico sobre los petroglifos gallegos Corpus Petroglyphorumm Gallaeciae (1935), escrito en latín, donde cataloga más de 200 localidades gallegas con una amplia documentación gráfica. Su trabajo rechaza las teorías expuestas por Obermaier, situando cronológicamente los grabados entre finales del megalitismo y la Edad de Bronce.

El estallido de la Guerra Civil estanca los estudios del arte rupestre galaico. Y posteriormente, con la dictadura franquista, los investigadores gallegos de ideologías opuestas al régimen se ven obligados a emigrar, con el consecuente estancamiento en la investigación. La gran excepción será Sobrino Lorenzo Ruza, hijo de Sobrino Buhigas, quien continua los pasos de su padre realizando aportaciones de aspecto cronológico y sobre su posible origen, además de incluir un amplio dominio territorial y bibliográfico. Serán estos temas los principales a desarrollar por los diferentes autores como Santos Junior.

A mediados de siglo se consolida la teoría cronológica comprendida entre el Período Megalítico y la Edad de Hierro, a excepción de Ferro Couselo. Este autor pospone su datación al período romano y época moderna, donde su funcionalidad sería simplemente delimitadora. Otro investigador destacado es el italiano Enmanuel Anati, autor de Arte rupestre nelle regioni occidentali de la Penisola Ibérica. Anati (1968) establece una triple cronología para datar los petroglifos en relación a su tipología. En primer lugar, incluye el estilo arcaico de los grabados zoomorfos en el período Epipaleolítico; mientras, los motivos estilizados los engloba dentro de Neolítico, para finalmente ubicar los elementos circulares, ídolos y armas entre el Eneolítico y Bronce final. Junto a Anati, en la década de los 70, otros historiadores italianos como Guilio Borgna, Fontani y Bessone han sido responsables de la positiva difusión internacional del arte rupestre gallego.

En Galicia, a principios de los 70, García Martínez encuentra una correspondencia temporal entre motivos figurativos y geométricos, refutando las teorías anteriores. García asienta las bases que seguirán Peña Santos y Vázquez Varela (1979), apuntando la Edad de Bronce como cronología coincidente. Otros autores como Álvarez Núñez y Velasco Souto (1979) señalan la correlación existente entre petroglifos y humedales, teoría defendida también por los artistas citados anteriormente. A medida que avanzamos en la década de los 80 las publicaciones se multiplican, pero sin aportaciones significativas. Los investigadores carecen de nuevas vías de estudio, agotando las líneas tradicionales defendidas por Peña Santos y Vázquez Varela. Poco a poco se buscan otras perspectivas para abordar el tema, con un ligero arranque en aspectos metodológicos y teóricos en los años 90 . El incremento es propiciado por el mayor número de investigadores y los estudios superiores con la especialidad de Arqueología en la Universidad de Santiago de Compostela. Otras aportaciones interesantes son la aparición de la arqueología espacial o contextual, la arqueología del paisaje, los estudios artísticos y estilísticos, junto a nuevas propuestas cronológicas.

Los investigadores de finales de siglo como Criado Boado y Santos Estévez se centran en las correspondencias espaciales y las distintas escalas de análisis, implicando un incremento de la complejidad de la temática y profundizando en aspectos interpretativos (Santos Estévez 2008). Se consolida una nueva rama de investigación arqueológica conocida como Arqueología del Paisaje, de larga tradición en países escandinavos y anglosajones. Con ella se estudian un conjunto de enfoques metodológicos, cuyo rasgo común es la investigación de la articulación de las sociedades con su entorno. El espacio es ordenado acorde con la concepción que del paisaje tenía la sociedad en la que se inscribe. (Santos Estévez 2008). Otros como Concheiro Coello, Gil Agra y 
Fábregas Valcarce vinculan los petroglifos con asentamientos de la Edad de Bronce (Concheiro Coello y Gil Agra 1994). Mientras, Filgueiras Rey, Rodríguez Fernández y Villoch Vázquez, identifican una clara relación entre grabados rupestres sencillos, principalmente cazoletas, con la existencia de túmulos megalíticos (Filgueiras Rey y Rodríguez Fernández 1994; Villoch Vázquez 1995).

En la última década del siglo pasado Richard Bradley, Fábregas Valcarce y Criado Boado, entre otros, realizan importantes investigaciones de campo en varias comarcas gallegas, con el consecuente aumento de los paneles rupestres conocidos (Fábregas 2012).

Por lo que respecta a la provincia de Lugo, en la década de los noventa, surgen nuevos trabajos en la zona inmediata a nuestro estudio, como es el caso de Antas de Ulla (Costas Goberna 1993/94) y Sarria. También, debemos mencionar la comarca contigua del Deza (Pontevedra), en el costado oeste de la Dorsal Meridiana Gallega, donde se han encontrado un gran número representaciones de armas, modificando así la distribución de estos motivos, que hasta la fecha eran muy escasos, casi casuales, en el interior (Fábregas 2009).

La evolución de los estudios de arte rupestre, como se observará a lo largo del artículo, deja al margen los grabados de la zona meridional de la provincia de Lugo. Salvo una breve mención en el Boletín de la Provincia de Lugo por parte de Carré Alvarellos (Carré Alvarellos 1949), lo obtenido hasta la fecha son pequeñas menciones en prensa o en obras divulgativas que carecen de valor histórico y/o científico.

La potencialidad de la zona hace que aficionados locales se interesen por dichos paneles y ayuden a la identificación de los mismos. Con toda probabilidad, los futuros trabajos en dicha área aumentarán el número, la calidad y la distribución de las estaciones.

\section{GRABADOS RUPESTRES EN EL SUR DE LA PROVINCIA DE LUGO}

Los trabajos realizados en la zona, Comarca de Chantada, Terras de Lemos y Quiroga, se han centrado en la prospección y catalogación de las estaciones rupestres, tomando como pauta para la delimitación del terreno la base de datos de la Delegación de Patrimonio de Lugo (Consellería de Cultura e Turismo de la Xunta de Galicia). Los resultados son muy positivos, con un total de cincuenta estaciones catalogadas, veinte de ellas inéditas.

Para una correcta identificación de cada panel rupestre se lleva a cabo una ficha de registro, en la cual se especifica el nombre del yacimiento, localización (ayuntamiento, parroquia, coordenadas UTM...), descripción de los motivos, tipo de soporte, emplazamiento y estado de conservación, indicando, en este último, grado y causas de alteración. A continuación, basándonos en los datos aportados en la catalogación, desglosaremos los puntos más significativos respecto a las estaciones estudiadas.

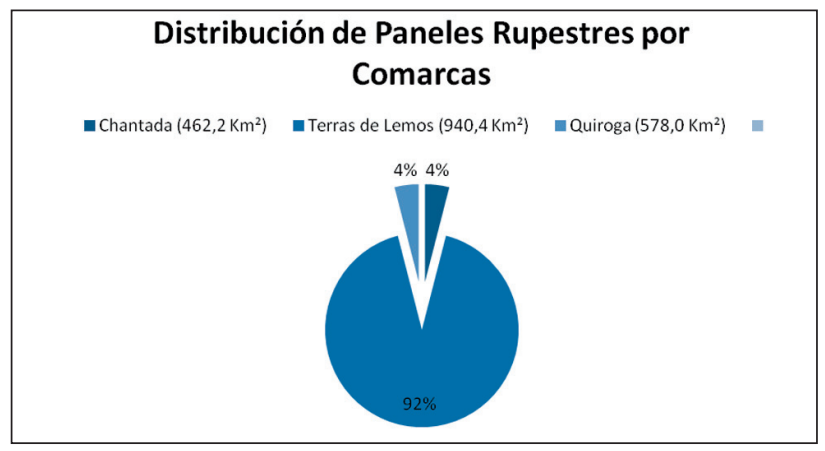

A Figura 2. Gráfico de distribución de paneles rupestres por comarcas.

Tabla 1. Distribución de paneles rupestres por comarcas.

\begin{tabular}{|l|l|c|c|}
\hline \multicolumn{3}{|c|}{ COMARCA DE CHANTADA } \\
\hline \multicolumn{1}{|c|}{ NOMBRE } & \multicolumn{1}{|c|}{ LUGAR } & \multicolumn{1}{c|}{ Y } \\
\hline Petroglifo de Airoá & Chantada-Pesqueiras & 603.038 & 4.721 .474 \\
\hline Pena das Mentiras & Chantada-Vilauxe & 602.886 & 4.714 .577 \\
\hline
\end{tabular}

\begin{tabular}{|l|l|c|c|}
\hline \multicolumn{2}{|c|}{ COMARCA DE TERRAS DE LEMOS } \\
\hline \multicolumn{1}{|c|}{ NOMBRE } & \multicolumn{1}{|c|}{ LUGAR } & X & Y \\
\hline A Escrita & Pantón-Toldaos & 616.115 & 4.708 .507 \\
\hline Petroglifo da Cancelada I & Pantón-Espasantes & 614.887 & 4.704 .501 \\
\hline Petroglifo da Cancelada II & Pantón-Espasantes & 615.302 & 4.704 .392 \\
\hline Petroglifo da Cancelada III & Pantón-Espasantes & 615.302 & 4.704 .392 \\
\hline Petroglifo das Carizas & Pantón-Espasantes & 613.096 & 4.704 .309 \\
\hline Pena da Cima da Costa & Pantón-Vilar de Ortelle & 607.445 & 4.709 .063 \\
\hline Petroglifo Monte San Román I & Pantón-Acedre & 610.644 & 4.702 .095 \\
\hline Petroglifo Monte San Román II & Pantón-Acedre & 610.637 & 4.702 .075 \\
\hline Petroglifo Monte San Román III & Pantón-Acedre & 610.637 & 4.702 .066 \\
\hline
\end{tabular}




\begin{tabular}{|c|c|c|c|}
\hline \multicolumn{4}{|c|}{ COMARCA DE TERRAS DE LEMOS } \\
\hline NOMBRE & LUGAR & $x$ & $Y$ \\
\hline Petroglifo Monte San Román IV & Pantón-Acedre & 610.631 & 4.702 .078 \\
\hline Petroglifo Monte San Román V & Pantón-Acedre & 610.671 & 4.701 .967 \\
\hline Petroglifo Monte San Román VI & Pantón-Acedre & 610.640 & 4.701 .957 \\
\hline Petroglifo Torre do Castro I & Pantón-Espasantes & 613.097 & 4.704 .269 \\
\hline Petroglifo Torre do Castro II & Pantón-Espasantes & 613.096 & 4.704 .309 \\
\hline Petroglifo Vilaxilde I & Pantón-Espasantes & 614.000 & 4.704 .127 \\
\hline Petroglifo Vilaxilde II & Pantón-Espasantes & 613.915 & 4.704 .260 \\
\hline Pena da Virxe & Pantón-Vilar de Ortelle & 607.688 & 4.710 .673 \\
\hline Petroglifo Exento de Pesqueiras & Pantón-Atán & 607.265 & 4.705 .207 \\
\hline Petroglifo Exento de San Román & Pantón-Acedre & 612.274 & 4.701 .462 \\
\hline Coviñas do Monte do Cura & Sober-Millán & 615.595 & 4.702 .019 \\
\hline Petroglifo do Agro I & Sober-Pinol & 620.130 & 4.694 .816 \\
\hline Petroglifo do Agro II & Sober-Pinol & 620.160 & 4.694 .711 \\
\hline Petroglifo Agro dos Llanos & Sober-Proendos & 615.983 & 4.700 .544 \\
\hline Petroglifo da Armenteira & Sober-Bulso & 619.595 & 4.697 .541 \\
\hline Petroglifo do Barcal & Sober-Pinol & 620.043 & 4.694 .786 \\
\hline Pena do Cabalo & Sober-Proendos & 617.063 & 4.701 .285 \\
\hline Petroglifo dos Cótaros/dos Toxaes & Sober-Figueiroá & 617.518 & 4.699 .840 \\
\hline Petroglifo da Ferrada & Sober-Santiorxo & 619.280 & 4.697 .466 \\
\hline Petroglifo Finca do Pombal & Sober-Proendos & 616.511 & 4.701 .126 \\
\hline Petroglifo de Froxán & Sober-Proendos & 616.799 & 4.700 .453 \\
\hline Petroglifo Lagos I & Sober-Proendos & 616.695 & 4.701 .006 \\
\hline Petroglifo Lagos II & Sober-Proendos & 616.947 & 4.700 .999 \\
\hline $\begin{array}{l}\text { Petroglifo das Laxas do Campo } \\
\text { da Cha }\end{array}$ & Sober-Pinol & 619.749 & 4.697.337 \\
\hline Petroglifo Laxa da Carreira & Sober-Bolmente & 616.113 & 4.696 .307 \\
\hline Petroglifo Monte do Coto & Sober-Proendos & 615.664 & 4.700 .414 \\
\hline Petroglifo Monte Veliños & Sober-Santiorxo & 619.306 & 4.697 .362 \\
\hline Petroglifo de Pedride & Sober-Proendos & 617.042 & 4.701 .248 \\
\hline Petroglifo de Prados & Sober-Figueiroá & 617.749 & 4.700 .032 \\
\hline Petroglifo do Preguiceiro & Sober-Santiorxo & 619.165 & 4.698 .080 \\
\hline $\begin{array}{l}\text { Petroglifo do Regueiro/ } \\
\text { Tapado do Monte }\end{array}$ & Sober-Anllo & 611.694 & 4.699 .042 \\
\hline Petroglifo do Toutileiro I & Sober-Pinol & 619.210 & 4.697 .137 \\
\hline Petroglifo do Toutileiro II & Sober-Pinol & 619.200 & 4.697 .123 \\
\hline Petroglifo do Val & Sober-Santiorxo & 618.510 & 4.697 .549 \\
\hline Petroglifo de Valderraña & Sober-Pinol & 619.643 & 4.695 .393 \\
\hline Pena do Xestal I & Sober-Proendos & 616.522 & 4.700 .991 \\
\hline Pena do Xestal II & Sober-Proendos & 616.476 & 4.700 .992 \\
\hline
\end{tabular}

\begin{tabular}{|l|l|c|c|}
\hline \multicolumn{3}{|c|}{ COMARCA DE OUIROGA } \\
\hline \multicolumn{1}{|c|}{ NOMBRE } & \multicolumn{1}{|c|}{ LUGAR } & X \\
\hline Petroglifo Fiais I & Quiroga-Cereixido & 651.158 & 4.702 .091 \\
\hline Petroglifo Fiais II & Quiroga-Cereixido & 651.102 & 4.702 .098 \\
\hline
\end{tabular}

\subsection{Tipologías}

Galicia, a diferencia del resto de la zona Atlántica Europea, presenta en sus grabados rupestres motivos de tipo naturalista como ciervos, caballos y figuras humanas. Estos elementos distintivos no se dispersan por todo el territorio galaico, sino que se acotan a una determinada zona dominada por río Lérez, en la provincia de Pontevedra. No ocurre lo mismo con los grabados geométricos, los más comunes y abundantes, distribuidos por los países europeos atlánticos y el interior gallego. Por consiguiente, nuestro análisis se centrará en la tipología geométrica, de carácter abstracto, localizada en las tres comarcas del sur lucense. 


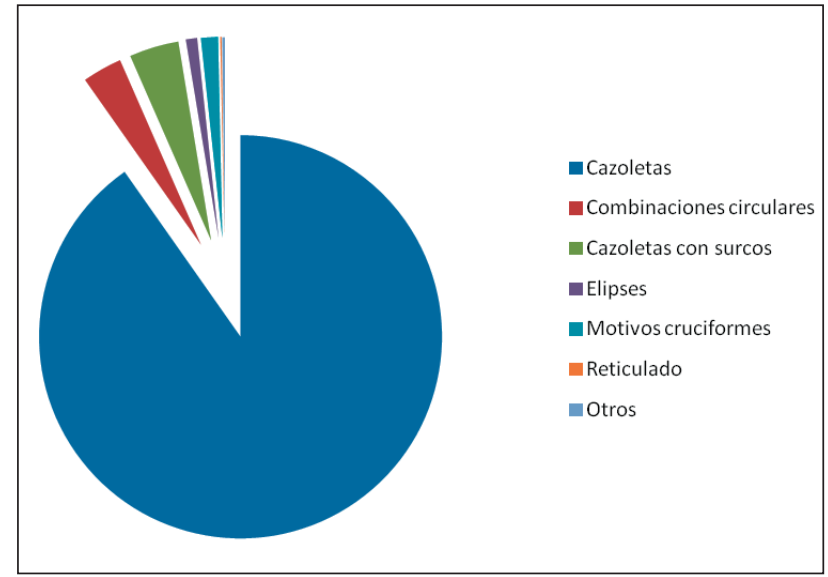

- Figura 3. Gráfico proporcional de los motivos analizados en el área de estudio.

Quiroga y Chantada poseen un número reducido de estaciones catalogadas, quizás propiciado por la carencia de estudios y prospecciones en ambas zonas. Además de escasos, los paneles decorativos son muy sencillos; presentan sólo cazoletas en el caso de Quiroga, acompañadas de alguna elipsis y surcos en Chantada. Al contrario que las anteriores, la comarca de Terras de Lemos conserva abundantes y variados motivos, concentrados en los ayuntamientos de Sober y Pantón.

Tabla 2. Clasificación de los motivos analizados en la zona sur lucense.

\begin{tabular}{|l|c|}
\hline \multicolumn{2}{|c|}{ TIPOLOGÍA Y NÚMERO DE REPRESENTACIONES } \\
\hline \multicolumn{1}{|c|}{ TIPOLOGÍA DEL MOTIVO } & $\begin{array}{c}\text { NÚMERO } \\
\text { DE REPRESENTACIONES }\end{array}$ \\
\hline Cazoletas & 795 \\
\hline Combinaciones circulares & 28 \\
\hline Cazoletas con surcos & 35 \\
\hline Elipses & 8 \\
\hline Motivos cruciformes & 12 \\
\hline Reticulado & 1 \\
\hline Otros & 2 \\
\hline TOTAL & 879 \\
\hline
\end{tabular}

\subsubsection{Motivos simples}

- Punto. Las cazoletas son sencillos hoyos excavados en la superficie de la roca, generalmente de forma hemisférica con base cóncava y un tamaño que oscila entre los $3-5 \mathrm{~cm}$ de diámetro, alcanzando 8-10 cm en sus variantes de mayor tamaño. Se encuentran frecuentemente agrupadas sin orden aparente, pero también formando parte con otras formas como surcos o círculos concéntricos. Concretamente encontramos setecientos noventa y cinco motivos, donde el número de agrupaciones por panel varía desde la centena hasta un sencillo

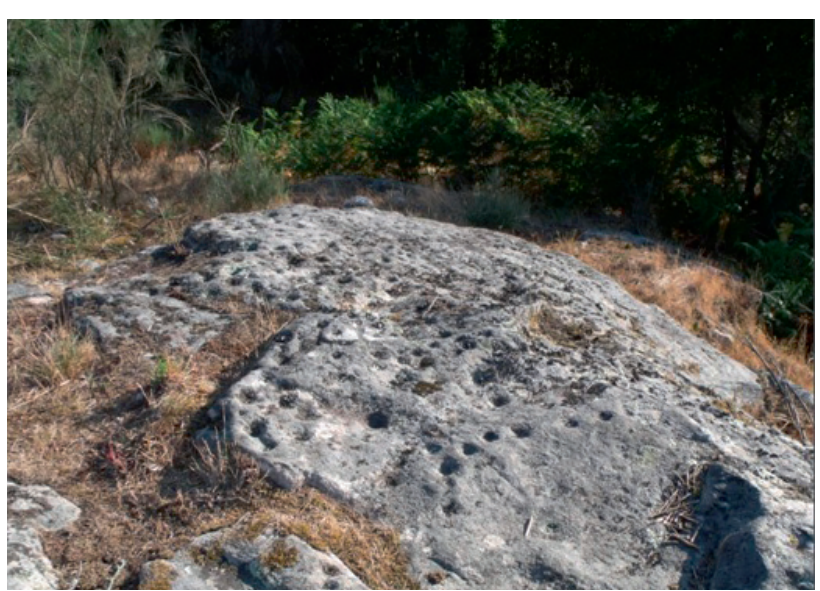

\ Figura 4. Petroglifo Cima da Costa, Vilar de Ortelle, Pantón.

conjunto de tres; En algunas ocasiones se han observado una única cazoleta aislada, pero siempre próxima a otros paneles.

- Línea. El surco, junto con la cazoleta, es uno de los motivos más simples que poseen las estaciones lucenses.

- Círculo. Se compone, a diferencia de la cazoleta, de una única circunferencia. Lo encontramos en el Petroglifo de Pena da Cima da Costa, Vilar de OrteIle (Pantón), aprovechando la morfología de la roca, posee $24 \mathrm{~cm}$ de diámetro.

- Elipse. Aparecen siempre vinculadas con las cazoletas, su tamaño varía de 10 a $15 \mathrm{~cm}$ de largo por 5 $\mathrm{cm}$ de ancho. En algunas ocasiones estas figuras se forma con la erosión de dos cazoletas, que se unen tras la pérdida del material pétreo que las separaba. Son escasos este tipo de grabados, sólo ocho. En el Petroglifo de Airoá, en Chantada, se conservan dos elipses de $15 \times 6 \mathrm{~cm}$, junto a otros motivos como cazoletas y surcos.

\subsubsection{Motivos compuestos}

- Combinación de elementos indeterminados.

- Motivo abstracto compuesto de líneas irregulares con puntos y círculos. La figura del Petroglifo de Os Cótaros, Sober, de gran esquematismo, presenta un círculo central con cazoleta, de la cual parten cuatro surcos que formar líneas irregulares y de distinta longitud, rematadas en cazoleta o en otro surco de menor prolongación. Es un motivo complejo de difícil interpretación.

- Figura en "phi". Morfológicamente poseen multitud de representaciones, que van desde la más sencilla, formada por una línea vertical cuya parte superior se ubica un óvalo o semicírculo cerrado, dándole ese aspecto del símbolo griego "phi", como el Pe- 
troglifo de Pedride. 0 de mayor complejidad como ocurre en el Petroglifo do Monte de San Román I, donde un entramado de surcos unidos a una cazoleta y a un óvalo forman una "phi". El parecido de estas representaciones con símbolos situados en sillares de templos medievales delata su cronología.

- Combinación de elementos lineales.

- Cuadrícula. Conjunto de líneas cruzadas en horizontal y vertical. El Petroglifo de Tapado do Monte exhibe el único elemento reticulado estudiado, compuesto de siete líneas horizontales cruzadas por cinco verticales.

- Cruz. Morfológicamente, los motivos cruciformes analizados son figuras muy sencillas, acompañados de cazoletas en A Escrita y Petroglifo Torre do Castro II, en Pantón, pero también junto a otros elementos de mayor complejidad como veremos en el Petroglifo Tapado do Monte. Tipos:

1. Griega. Figura formada por dos líneas rectas, de brazos iguales, que se atraviesan. En A Escrita, en Pantón, tres de las siete cruces que exhibe el panel utilizan un surco que rodea todo el perímetro de la roca como brazo horizontal.

2. Latina. Figura formada por dos líneas rectas que se atraviesan, con el travesaño en el primer cuarto del palo. En el panel anterior también se observa este tipo de cruz.

- Combinación de elementos circulares y puntos. Son, sin duda, el conjunto más característico de todo el arte rupestre prehistórico gallego. Se encuentran integradas por figuras de líneas curvas, en especial el círculo en sus más diversas combinaciones. Sin duda, forman una compleja serie de figuras abstractas de gran variedad, pero que reiteran, a menudo, un número de temas básicos. En Sober se concentra el mayor número grabados, destacando los Petroglifos Pena do Xestal I y Pena do Xestal II. Este último posee un único motivo, de $43 \mathrm{~cm}$ de diámetro, compuesto por ocho círculos concéntricos con cazoleta central, de la cual parten dos surcos. Los restantes motivos se componen de 5 a 1 solo círculo, como se puede comprobar en el Petroglifo exento de Acedre en Pantón, con un único círculo del cual surgen dos surcos.

- Combinación de círculo y cazoleta. Conjunto compuesto por la unión de un círculo y una cazoleta central. Se observa en los petroglifos de Froxán, Tapado do Monte y Pombal, todos ellos en Sober.
- Combinación de 2 círculos y cazoleta. El motivo presenta dos círculos concéntricos y una cazoleta central. Es el más representativo, son siete las combinaciones de este tipo. Las hallamos en los petroglifos de Pena do Xestal I, Tapado do Monte y Cótaros, en Sober.

- Combinación de 3 círculos y cazoleta. La agrupación está formada por tres círculos concéntricos y una cazoleta central. Los cinco grabados existentes se distribuyen por los petroglifos de Pombal, Froxán y Cótaros, en Sober, este último con cuatro representaciones de estas caracteristicas.

- Combinación de 4 círculos y cazoleta. El motivo se compone de cuatro circunferencias concéntricas y una única cazoleta central. El único ejemplo se encuentra en el Petroglifo exento de Pesqueiras, en Pantón.

- Combinación de 5 círculos y cazoleta. Conjunto formado por cinco círculos concéntricos y una cazoleta central. Existe un único ejemplar en el Petroglifo Pena do Xestal I, en Sober.

- Combinación de 8 círculos y cazoleta. Composición formada por ocho círculos concéntricos y una cazoleta central. Al igual que los anteriores, sólo poseemos un único grabado en el Petroglifo Pena do Xestal II.

- Combinación de puntos y líneas. Otra variable tipológica es la unión de cazoletas con surcos, formando un motivo compuesto. Son treinta y cinco los soportes que poseen conjuntos de cazoletas agrupadas por surcos. El grupo más sencillo y a su vez más abundante es el formado por dos cazoletas unidas por un único surco, como podemos comprobar en el Petroglifo do Preguiceiro en Sober, donde encontramos siete motivos compuestos formados por la unión de dos cazoletas y un único surco. También existen uniones de tres, cuatro y cinco

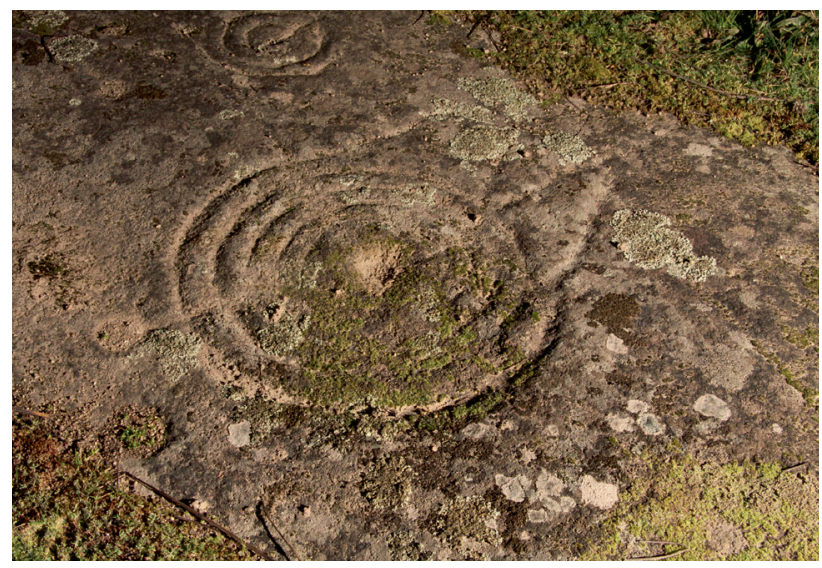

A Figura 5. Detalle del Petroglifo Pena do Xestal I, Proendos, Sober. 


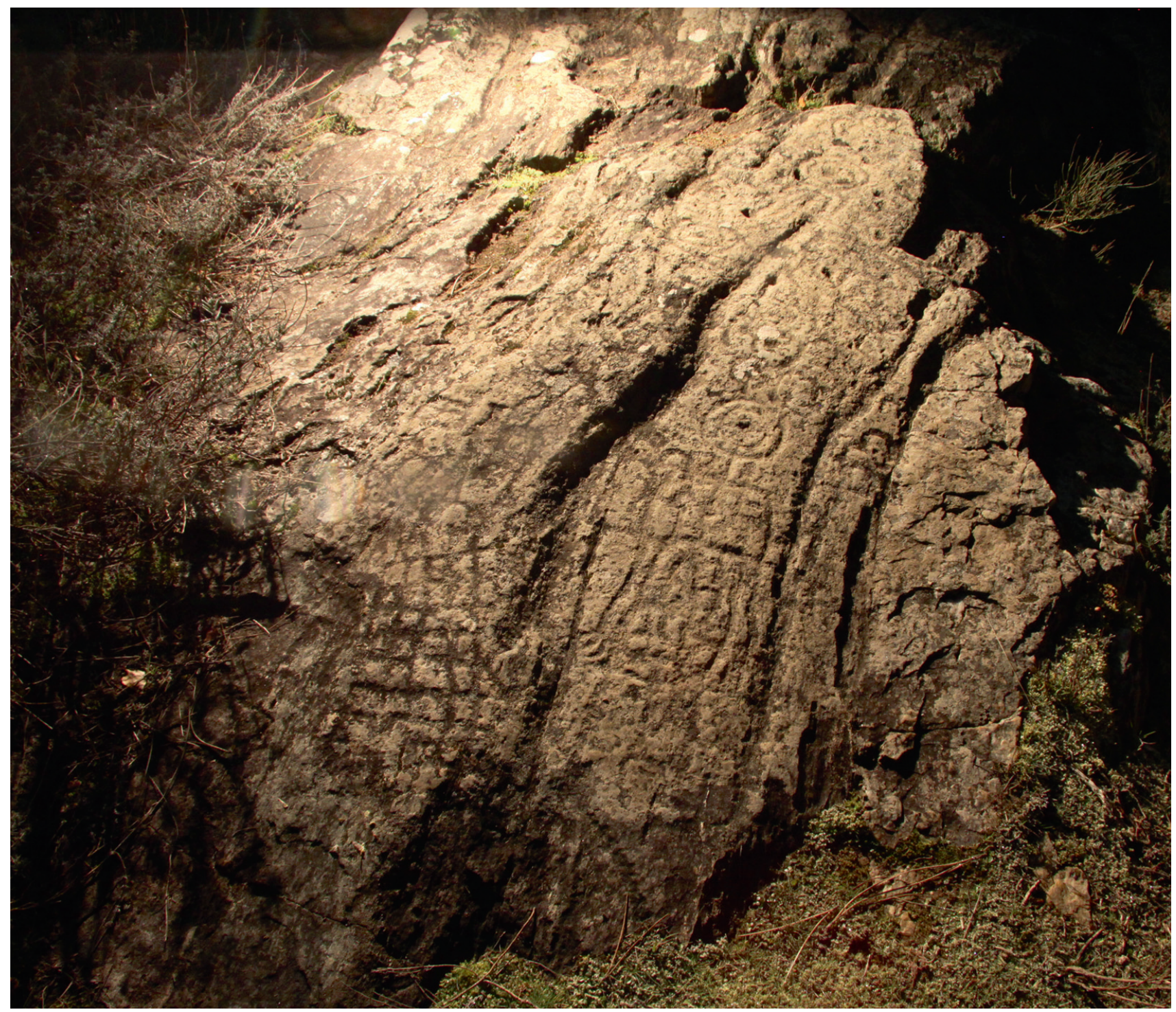

ム Figura 6. Fotografía del petroglifo do Regueiro/Tapado do Monte, Anllo, Sober.

cazoletas por medio de un surco como ocurre en el Petroglifo do Monte de San Román en Pantón, donde se dan los tres casos. Dentro de esta variedad se puede incluir la Pena do Cabalo en Sober, donde por medio de la unión de tres cazoletas se configura una figura indeterminada, que algunos identifican con un caballo, de ahí su denominación.

Existen soportes que poseen una gran variedad y riqueza en sus representaciones. Hablamos de los petroglifos Tapado do Monte y Cótaros, ambos en Sober, que merecen un espacio a parte para su análisis. En el Petroglifo Tapado do Monte, realizado sobre un gran soporte esquistoso, se distribuye un amplio número de figuras: en la parte oeste encontramos ocho combinaciones circulares variadas, junto a quince cazoletas, un extenso entramado de surcos y un reticulado de difícil interpretación. Por el contrario, en la zona este se disponen cinco cruciformes y un motivo inde- terminado formado por un semicírculo dividido a la mitad por una línea vertical. Las representaciones de la parte oeste son características del estilo prehistórico, salvo el reticulado de difícil adscripción, mientras que las cruces y la figura indeterminada son de época histórica.

El Petroglifo dos Cótaros, a diferencia del anterior, se emplaza sobre un soporte granítico, en el cual se distribuyen agrupaciones de cazoletas, combinaciones circulares, entramados de surcos y una combinación de elementos de difícil clasificación. La erosión producida por las inclemencias meteorológicas no permite visualizar las representaciones con claridad.

Se ha comprobado la variedad morfológica de tipo abstracto de los petroglifos del sur de la provincia, destacando Cótaros y Tapado do Monte, donde se concentran la mayor diversidad de figuras. Las tipologías estudiadas, cazoletas, combinaciones circulares, reticulado y surcos, son la prueba de la pluralidad de los paneles. 
Tabla 3. Clasificación y desglose de los motivos rupestres en las tres comarcas estudiadas.

\begin{tabular}{|c|c|c|c|}
\hline \multirow{4}{*}{$\begin{array}{l}\text { MOTIVOS } \\
\text { SIMPLES }\end{array}$} & Punto & & \\
\hline & Línea & & \\
\hline & Círculo & & \\
\hline & Elipse & & \\
\hline \multirow{17}{*}{$\begin{array}{l}\text { MOTIVOS } \\
\text { COMPUESTOS }\end{array}$} & \multirow[t]{2}{*}{ Combinación de elementos indeterminados } & \multicolumn{2}{|c|}{$\begin{array}{l}\text { Motivo abstracto compuesto de líneas irregulares con } \\
\text { puntos y círculos }\end{array}$} \\
\hline & & \multicolumn{2}{|c|}{ Figura en "phi" } \\
\hline & \multirow[t]{3}{*}{ Combinación de elementos lineales } & \multicolumn{2}{|c|}{ Cuadrícula } \\
\hline & & \multirow[t]{2}{*}{ Cruz } & Latina \\
\hline & & & Griega \\
\hline & \multirow{6}{*}{$\begin{array}{l}\text { Combinación de elementos circulares } \\
\text { y puntos }\end{array}$} & \multicolumn{2}{|c|}{ Un Círculo y un punto } \\
\hline & & \multicolumn{2}{|c|}{ Dos círculos y un punto } \\
\hline & & \multicolumn{2}{|c|}{ Tres círculos y un punto } \\
\hline & & \multicolumn{2}{|c|}{ Cuatro círculos y un punto } \\
\hline & & \multicolumn{2}{|c|}{ Cinco círculos y un punto } \\
\hline & & \multicolumn{2}{|c|}{ Ocho círculos y un punto } \\
\hline & \multirow[t]{6}{*}{ Combinación puntos y líneas } & \multicolumn{2}{|c|}{ Dos puntos y una línea } \\
\hline & & \multicolumn{2}{|c|}{ Tres puntos y una línea } \\
\hline & & \multicolumn{2}{|c|}{ Cuatro puntos y una línea } \\
\hline & & \multicolumn{2}{|c|}{ Cinco puntos y una línea } \\
\hline & & \multicolumn{2}{|c|}{ Seis puntos y una línea } \\
\hline & & \multicolumn{2}{|c|}{ Siete puntos y una línea } \\
\hline
\end{tabular}

\subsection{Técnica}

Los trabajos sobre arte rupestre se centran principalmente en el estudio estilístico y/o interpretativo de los grabados, donde el apartado técnico es escaso o simplemente inexistente. Por este motivo, al carecer de base bibliográfica, nos vemos obligados a realizar una escueta mención de los conocimientos técnicos empleados en la realización de las representaciones.

La sección transversal ha sido clave para definir el útil empleado y, a su vez, la cronología del grabado. Encontramos dos tipos de secciones:

- Sección transversal en U. Los surcos son muy abiertos, semejantes a un óvalo partido por la mitad, suave al tacto y con una anchura el doble que su altura.

- Sección transversal en V. Los bordes son muy angulosos y las paredes rectas y ásperas, en las que se aprecian huellas realizadas por instrumentos afilados y de punta fina.

El primer tipo se relaciona con los petroglifos prehistóricos, realizados con instrumentos líticos. Su aspecto es el resultado de siglos de erosión climática. Al contrario que los anteriores, el segundo tipo corresponde con petroglifos históricos, realizados en época medieval con útiles metálicos. Estas afirmaciones se extienden hasta los años ochenta, a partir de esa fecha se realizan análisis más exhaustivos incidiendo en dos tipologías:

- Piqueteado, técnica realizada por medio de pequeños golpes con un percutor.

- Abrasión, que consiste en el desgaste de la superficie por medio de la fricción.

En el caso de los petroglifos prehistóricos estudiados defendemos la técnica por abrasión, más factible en las cazoletas, dada la huella analizada, pero siempre con precaución, porque el grado de erosión de los motivos hace que no tengamos una certeza absoluta, a falta de análisis más exhaustivos.

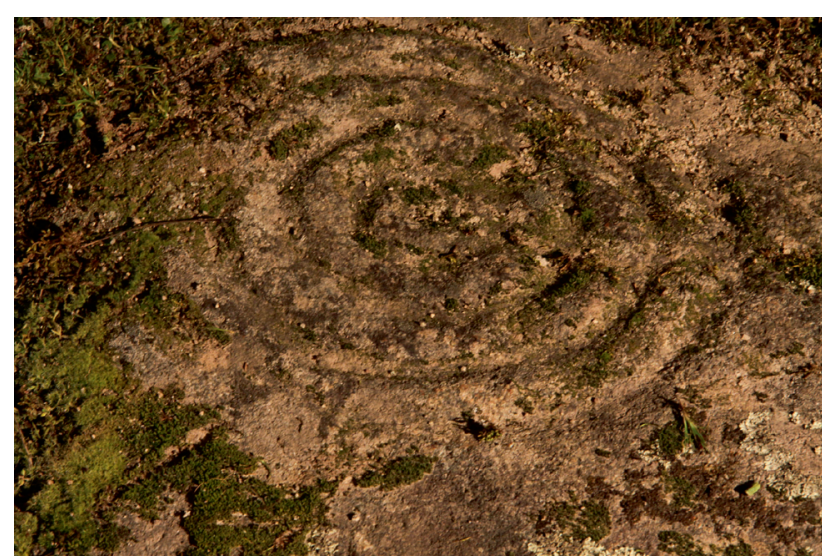

A Figura 7. Detalle Surcos del Petroglifo de Pena do Xestal, Proendos, Sober. 


\subsection{Ubicación de los motivos}

Con el megalitismo tiene lugar una radical transformación en el proceso de humanización del espacio. La llegada del Neolítico es determinante para que el paisaje gallego empiece su período de delimitación, donde las condiciones climáticas, topográficas, edáficas y clinométricas son claves para la ocupación de un determinado territorio. Las estructuras megalíticas ayudan a comprender el volumen de población existente en Galicia, que es relativamente equilibrado, concentrándose en mayor número en zonas Ilanas, valles e incluso gándaras, frente a las zonas de fuerte pendiente (Pérez Alberti 1993b: 29-37). El espacio se ordena atendiendo a las facilidades para la agricultura y ganadería, donde los pueblos nómadas, básicamente cazadores tornan a sedentarios. Los núcleos de población serán de pequeñas dimensiones, ubicados a 150-500 metros de altura sobre el nivel del mar. La presencia de ríos y regatos será fundamental para la defensa y el abastecimiento de la comunidad. El agua favorece la dispersión de células de población, con una estructura donde el elemento bélico jerarquizaba los intereses de organización espacial (Pérez Alberti 1993b: 33).

A la hora de realizar un análisis territorial del arte rupestre se debe tomar como punto de partida los asentamientos de sus antecesores, claramente vinculados para Villoch o Santos, e incluso temáticamente para Fábregas y Penedo (Bradley y Fábregas 1996: 103). De ellos sólo conservamos sus túmulos, que sirven como referencia indirecta del hábitat ocupacional. Los grabados rupestres, al igual que los túmulos megalíticos, se extienden por las cuatro provincias gallegas, pero su mayor concentración se ubica en las zonas costeras. Concretamente, son los motivos abstractos, círculos concéntricos y cazoletas, los que poseen una mayor dispersión a nivel autonómico y europeo-atlántico (Islas Británicas, Escocia, Escandinavia...). La excepción se encuentra en los motivos naturalistas de las zonas costeras gallegas, únicos en el panorama internacional, también ausentes en las provincias interiores de Galicia.

\subsubsection{El paisaje}

Las estaciones rupestres se encuentran dentro de un paisaje previamente delimitado por sus antecesores neolíticos, mediante la construcción de túmulos megalíticos. En las inmediaciones de los petroglifos estudiados hallamos presencia de este tipo de túmulos. Concretamente en la feligresía de Proendos, comarca de Monforte de Lemos, ocho estaciones rupestres comparten protagonismo con dos túmulos megalíticos. Las tres comarcas catalogadas se vinculan directamente a dos accidentes geográficos de vital

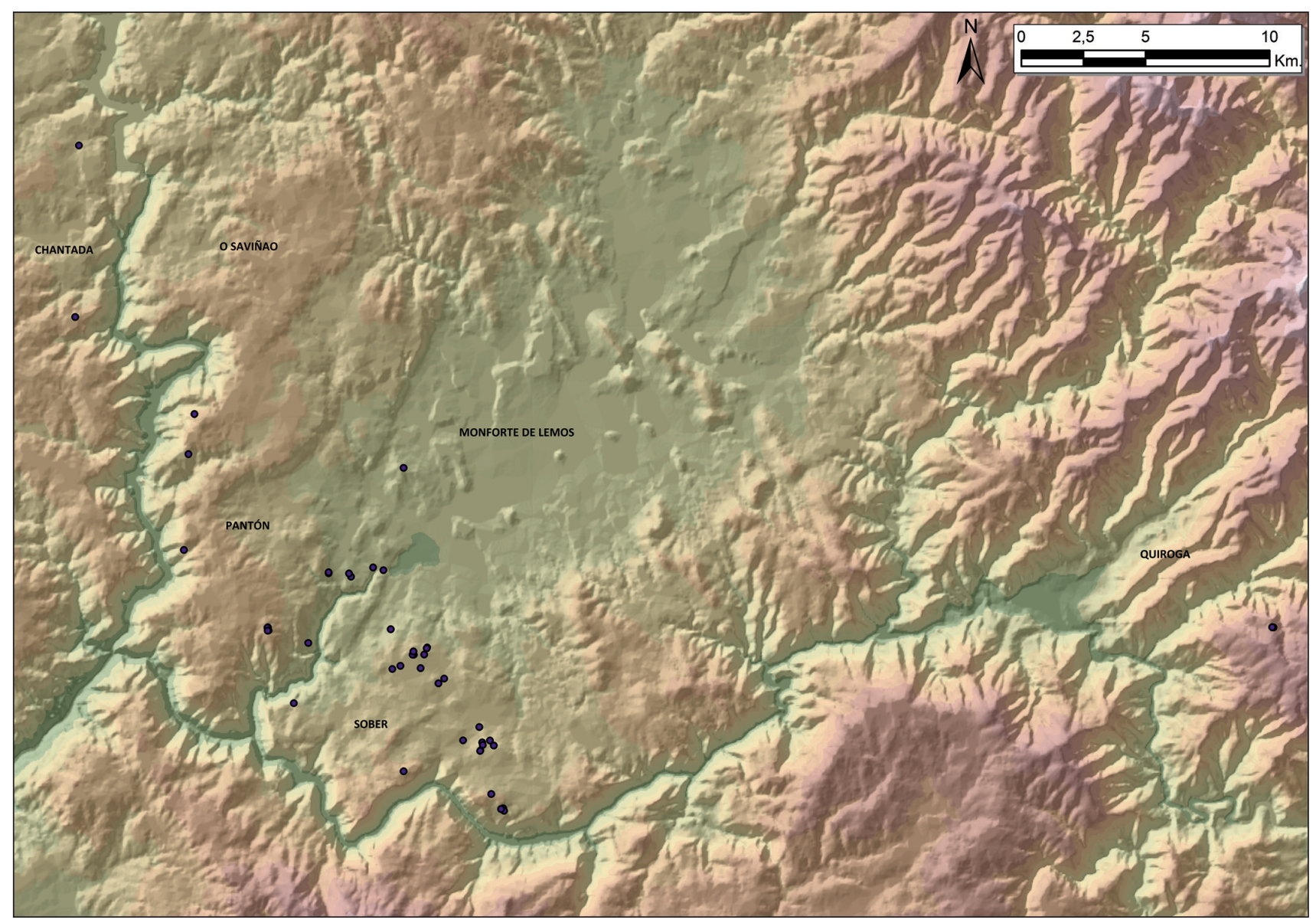

A Figura 8. Distribución de las estaciones en el suroeste de Lugo. 
importancia para la zona, los ríos Miño y Sil, con sus numerosos afluentes (Búbal, Cabe, Lor...). El río Miño bordea la depresión de Monforte por el Oeste, hundiéndose en Chantada (700 metros) y el Sil lo hace más al Sur, formando una pronunciada pendiente entre Quiroga y Os Peares, en este enclave está el municipio de Sober. La morfología del valle del Sil y Os Peares es muy cerrada y posee pendientes que se acercan a los $35^{\circ}$. A su vez, Quiroga posee una pequeña depresión. Por el contrario, la depresión Monforte-Sarria se caracteriza por una morfología plana y abundante de sedimentos de diferente tipo, entre los que destacan terrazas fluviales. Existen, por lo tanto, áreas con fuerte incisión fluvial, característica vinculada directamente al predominio de grabados rupestres estudiados.

La zona predominante es la penillanura, donde las estaciones gozan de un dominio visual del entorno inmediato. Se sitúan, mayoritariamente, a una altura de 500-700 metros, confirmando de nuevo la importancia del control visual del paisaje por parte de nuestros antepasados.

El petroglifo, al igual que otras manifestaciones prehistóricas, se mimetiza perfectamente con el medio en una plena integración entre ambos. Su ubicación no es casual, busca intencionadamente la cercanía de zonas húmedas que, además, posean buena visualización del entorno que los rodea.
Otro factor a destacar es la cercanía de los yacimientos rupestres a caminos de tránsito, muchos de ellos de tradición histórica como el Camino Real en Sober. Concretamente, en las proximidades de este camino hallamos siete paneles de cazoletas con mayor o menor cercanía e, incluso, una de ellas se ubica en el propio camino.

\subsubsection{La roca}

El granito es la roca predominante en las estaciones rupestres estudiadas. Sin duda, este hecho es propiciado por la abundancia de afloramientos graníticos que poseen las tierras gallegas. Es de naturaleza compacta y dura, de dificil talla, pero de gran durabilidad. Estas características son favorables para que los grabados rupestres subsistan hasta nuestros días. Además del granito hallamos estaciones de pizarra en los Petroglifos de Fiais (Fiais, Cereixido, Quiroga); y rocas de esquisto en el Petroglifo de Nogueira (Anllo, Sober, Monforte de Lemos) y en los Petroglifos del Monte de San Román (Acedre, Pantón, Monforte de Lemos). El esquisto posee un color rosáceo y se divide con facilidad en láminas, al igual que la pizarra.

Las rocas se disponen en su mayoría en posición horizontal o subhorizontal, y se levantan del suelo de 70-1,20 metros en su mayoría. En menor número encontramos esta-

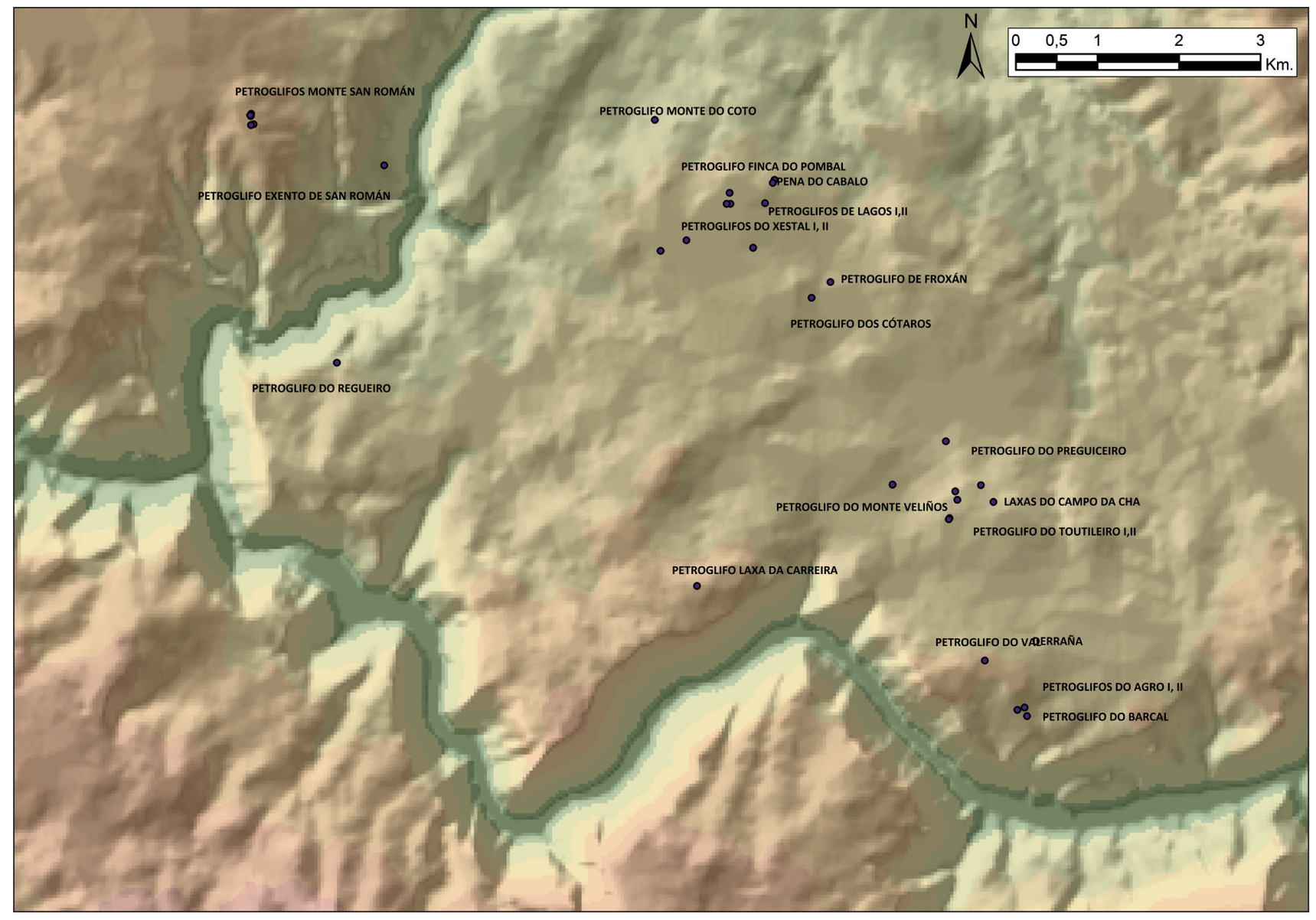

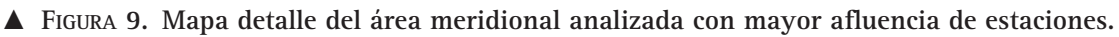




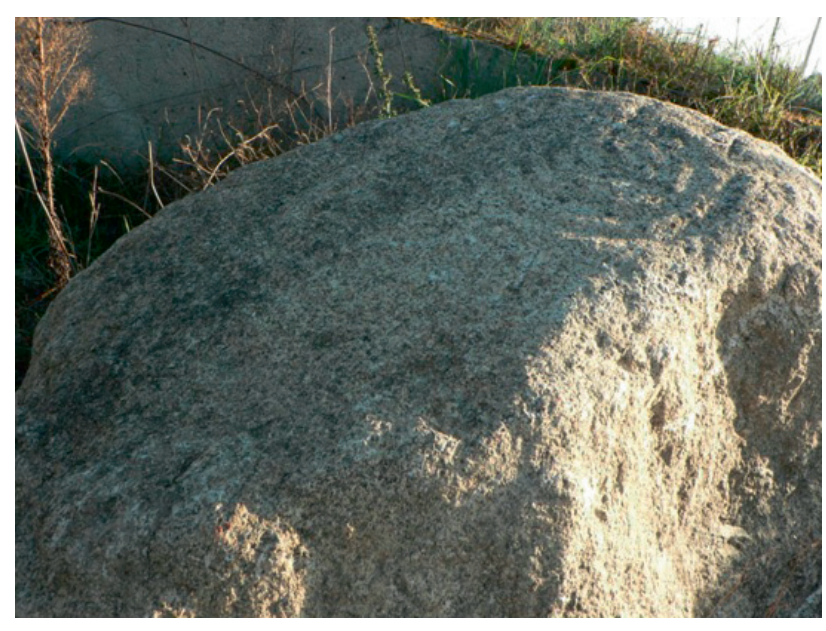

A Figura 10. Petroglifo exento de Atán, Pantón.

ciones a ras de suelo. Su superficie tiende a ser regular, con pocas grietas, buscando la homogeneidad del panel-lienzo. Su tamaño es muy variado, los soportes se sitúan entre los 2-10 metros de longitud y los 1-6 metros de anchura.

Los datos anteriores confirman que el tamaño y altura del panel no era importante a la hora de plasmar en el los motivos. Por el contrario, si lo era su ubicación. Los motivos no son fáciles de visualizar a cierta distancia, pero poseen en su mayoría buena visualización panorámica. En cuanto a la orientación, no se vinculan a una disposición determinada, pero señalamos que varios de los paneles decorados se distribuyen en la parte sur del lienzo granítico (0 Barcal, Laxa da Carreira, ambas en Sober).

\subsection{Análisis simbólico}

Realizar un análisis simbólico de las estaciones estudiadas es una ardua tarea debido a la gran distancia temporal que nos separa de nuestros antepasados. Retroceder mentalmente es labor imposible, por lo que nuestras opiniones son sólo eso, meras opiniones relativas y nunca absolutas.

Las sociedades creadoras de esta simbología eran complejas y claramente evolucionadas, donde la agricultura y la ganadería eran importantes actividades económicas. Concretamente, a finales del Calcolítico la agricultura se desarrolla sobre un terreno deteriorado por la tradición del cultivo de rozas, el cambio climático y una probable presión demográfica relativa. Ésta última puede estar en relación con el desarrollo de la jerarquización social, visible en los enterramientos individuales de este período, junto a la representación de guerreros armados en los grabados rupestres (Costas Goberna y Hidalgo Cuñarro 1998: 45-47). Las sociedades del Calcolítico representan en sus grabados tareas ganaderas y cinegéticas, pero no labores agrícolas, ya que no se ha estudiado ni una sola estación que muestre tal actividad. De este modo, concluimos que eran reducidas las representaciones sobre la vida cotidiana.
Tenemos una sociedad inteligente y con diversidad social que utiliza técnicas de grabado para llevar a cabo dos tipos de representaciones, una claramente relacionada con la realidad (animales, hombres, armas...) y otra, más abundante y extendida, de tipo abstracto (cazoletas, círculos, surcos...). Es esta última tipología, de temática abstracta, la que se extiende por todo el territorio gallego y, concretamente, por el sur de la provincia de Lugo. Analizaremos las teorías relativas a esta temática e incluiremos un breve apartado sobre las leyendas, de tradición oral y popular, creadas para explicar el significado del arte rupestre.

\subsubsection{Temática y simbología}

En el apartado 3.1. se ha comprobado que los motivos estudiados en el sur de la provincia de Lugo son de tipo abstracto, lo que dificulta la investigación de su significado. Las primeras apariciones de arte rupestre se relacionaron con distracciones de pastores desocupados, que realizaban estos grabados por mero aburrimiento. Incluso hoy en día, vecinos próximos a los yacimientos mantienen esa misma teoría. Con los años comienzan a incrementarse el número de investigadores y significados: trampas de caza, signos astronómicos, escritura semiesférica, altares de sacrificios, planos, etc. Actualmente la teoría que cobra fuerza es la señalización de lugares de culto (González Reboredo 1969: 7-14) o zonas en las que se realizan rituales de iniciación, donde el autor de los grabados sería un "intermediario" entre la comunidad y la divinidad, enfatizando las desigualdades de una sociedad estructurada jerárquicamente (Costas Goberna y Hidalgo Cuñarro 1996: 101). Hoy en día, ese artífice comparte similitudes con actuales chamanes que habitan en zonas de Sudamérica y Oceanía (Clottes y Lewis-Williams 2001), principalmente en dos aspectos: El primero, su papel privilegiado dentro de la comunidad, donde es el encargado de realizar los ritos y crear las representaciones. El segundo aspecto son las vinculaciones directas entre las visiones de estos personajes, producidas tras la ingesta de alucinógenos, con nuestros petroglifos. Además, estudios neurológicos nos hablan de imágenes formadas por los nervios ópticos, que pueden aparecer de la misma forma en todas las sociedades.

Lo cierto, es que son símbolos sencillos y comunes extendidos por los diferentes grupos culturales del planeta. Un mismo motivo puede tener diferentes interpretaciones atendiendo a la forma de representarse en un panel y de combinarse, por no hablar de las diferencias entre las mentalidades de distintas épocas. Por ello se deben tener precauciones a la hora de analizar sus significados.

Por otro lado, si atendemos al factor ubicación, estudiado en el apartado 3.2., la importancia del lugar o de la roca se encuentra directamente relacionada con el número de representaciones que posee. En nuestro estudio se han catalogado paneles que exhiben desde tres cazoletas hasta 


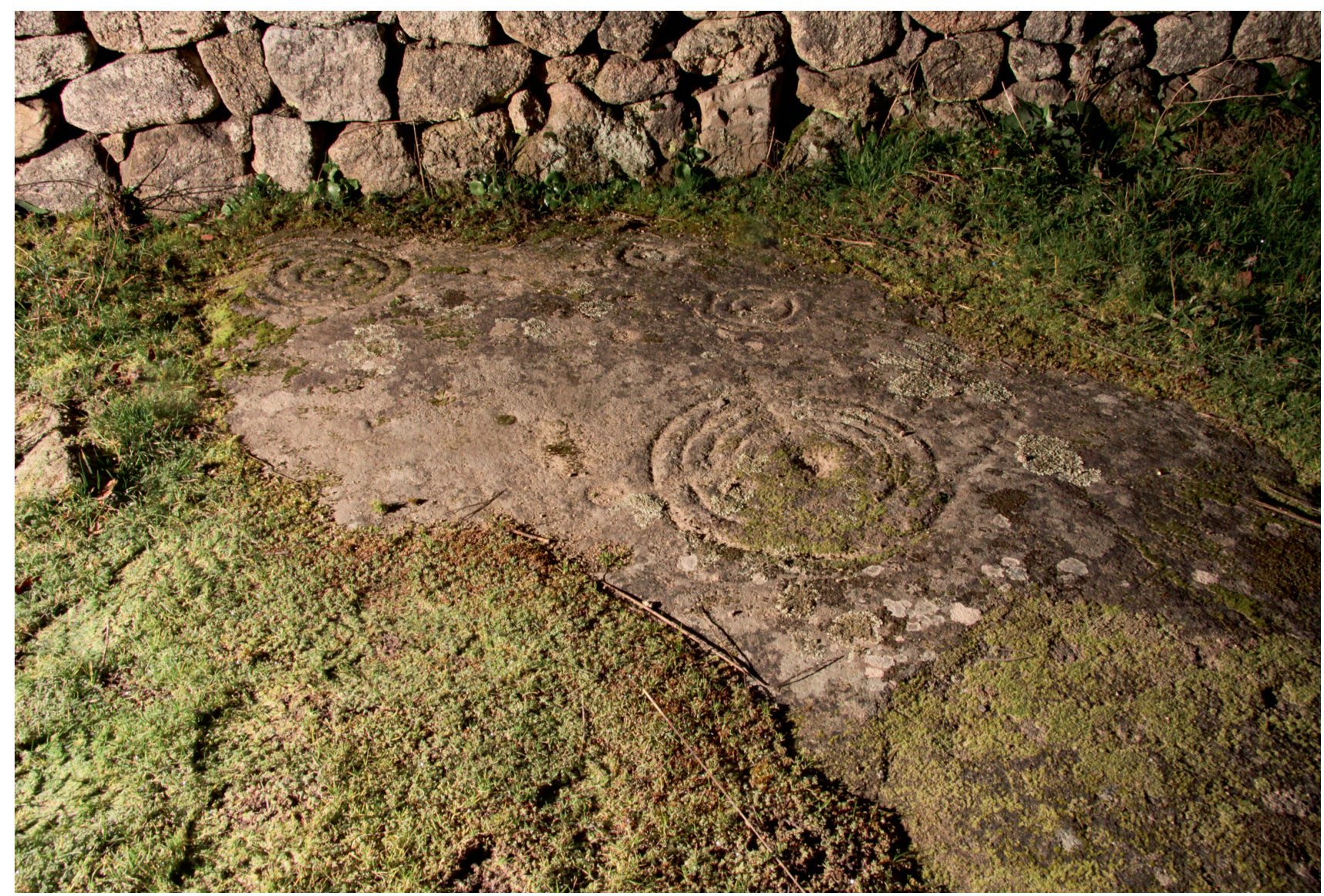

\ Figura 11. Círculos concéntricos del petroglifo de Pena do Xestal I, Proendos, Sober.

la centena, indistintamente del tamaño del soporte. Es decir, existen grandes piedras con un número reducido de grabados, como el Petroglifo de Laxas do Campo da Cha, Sober $(5,30 \times 3,40 \mathrm{~m})$ con sólo 6 cazoletas; y otras de tamaño medio repletas de elementos, al igual que el Petroglifo de Prados, Sober $(1,77 \times 1,48 \mathrm{~m})$ con 18 cazoletas. Destacan los dos paneles denominados completos, Petroglifo do Cotarro y Tapado do Monte, ambos en Sober, donde prácticamente todo el soporte se encuentra cubierto por grabados de variada configuración, posiblemente vinculados a la importancia de la roca y del lugar.

Las rocas se encuentran en su mayoría en zonas de gran visibilidad, distribuidas en las laderas próximas a los ríos Miño, Sil y Cabe. Los paneles se orientan hacia estos accidentes geográficos con una clara intencionalidad. Además, las estaciones se hallan a pocos metros de riachuelos 0 zonas de estancamiento de aguas.

La misma importancia que posee el agua para ubicar un panel decorativo la posee para su representación. Las cazoletas y elipsis son propensas al estancamiento de las aguas fluviales, mientras que los surcos y motivos circulares presentan relieves por los cuales puede fluir el líquido. El agua se vincula con la fertilidad, puesto que es fuente de toda vida. Quizás, este mismo concepto se persiga con las numerosas cazoletas dispuestas en los paneles, muchas de ellas unidas a surcos, como ocurre en el Petroglifo Monte de San Román I en Pantón.

Los motivos circulares, menos abundantes que los anteriores, se encuentran doblemente relacionados con este líquido. Además del motivo anterior, relacionado con el fluir de las aguas por sus relieves, encontramos en su morfología el aspecto que posee el agua en calma cuando se le arroja una piedra, creando numerosos círculos concéntricos que se expanden hacia el exterior. En el Grupo 28 de Outeiro do Lombo da Costa en Cotobade, Pontevedra, un grupo de cérvidos beben de una combinación circular y de sus surcos. Esta representación nos aporta un dato verdaderamente interesante, donde la vinculación entre una charca y un grabado circular no lleva a errores.

A continuación nos centraremos en los restantes motivos abstractos, formado por elementos minoritarios: cruces, figuras en "phi", cuadrículas e indeterminados. Los motivos cruciformes se alejan del denominado Grupo Galaico de Arte Rupestre, dada su datación en época histórica. En la actual catalogación se han recopilado sólo tres paneles con cruces. En cuanto a su significado podemos diferenciar por su emplazamiento dos teorias al respecto:

- La primera, motivos de demarcación o acotamiento, relativa a señales de término, es decir, marcos deli- 
mitadores que acotarían el espacio para fijar territorios sometidos a prestaciones y tributos, deslindar montes o terrenos de pastos. El factor económico y social de estos delimitadores era vital en época feudal (Costas Goberna e Hidalgo Cuñarro 1998: 159). Concretamente, la piedra de A Escrita en Pantón, se encuentra dentro de esta tipología, pues es un marco que separa dos parroquias limítrofes, Toldaos y Pantón.

- La segunda hipótesis se refiere a la cristianización de lugares durante el Medievo, con la intencionalidad de anular o borrar los grabados paganos. Ejemplo de ello son el Petroglifo da Torre do Castro II, en Pantón, y el Petroglifo de Tapado do Monte, en Sober. El primero, ubicado en el Castro de Espasantes, presenta una cruz próxima a varias cazoletas, posible muestra de cristianización de un territorio pagano. Lo mismo sucede en el segundo caso, el panel se encuentra repleto de círculos concéntricos y otros motivos prehistóricos, a los cuales se les han añadido cinco motivos cruciformes, con una intención clara, la de anular el significado pagano de la piedra y reconvertirlo.

Una simbología similar a la anterior la poseen las figuras en "phi", por sus paralelismos con construcciones del Medievo, concretamente con las inscripciones de los sillares distribuidos en los templos y castillos del Noroeste de la Península Ibérica (Costas Goberna e Hidalgo Cuñarro 1998: 147-151). Dos han sido los motivos catalogados como "phi" en el sur lucense, Petroglifo de Pedride, en Sober y Petroglifo de San Román I, en Pantón. Este último, de morfología más compleja, es similar a un delimitador medieval de Oia, Pontevedra. El panel del monte de San Román se encuentra desplazado de su emplazamiento original y próximo a la delimitación de tres parroquias: Acedre, Cangas y Frontón. Es probable que función haya sido delimitadora, como sucede en el mencionado grabado de Oia.

En cuanto a la única retícula catalogada en el Petroglifo de Tapado do Monte en Sober, semeja un tablero de juego ajedrezado de época histórica, datados desde la antigüedad clásica hasta el Medievo, además su proximidad a cruces medievales puede indicar su período de realización. Aún así, debemos ser cautos a la hora de atribuir un significado.

Finalmente nos detendremos en el panel Pena do Cabalo, en Sober, denominado así por el parecido que posee para las gentes del lugar con el cuadrúpedo. Lo cierto, es que su grado de esquematismo no nos permite afirmar con rotundidad que su creador quisiera realizar dicha representación equina. En la comarca limitrofe de Sarria encontramos una figura similar a la Pena do Cabalo, donde los autores lo denominan figura de dudosa interpretación. Estas tres cazoletas unidas por un surco no muestran similitudes con las demás representaciones de animales localizadas en su mayoría en las vertientes de río Lerez, por consiguiente, su significado es una incógnita para nosotros.

Lo evidente no es necesario explicarlo, las imágenes, cuando se representan, poseen una simbología implícita que, a su vez, perpetúa en la piedra a lo largo de los siglos.

\subsubsection{Leyendas}

El ser humano tiende a explicar aquellos sucesos o entidades que lo rodean. La presencia de rocas decoradas con grabados, al igual que otras manifestaciones prehistóricas, desencadena una serie de leyendas que podemos englobar en dos tipos: religiosas y fantásticas.

Las leyendas de tipo religioso surgen en muchas ocasiones con la misma intencionalidad cristianizadora que las cruces grabadas que analizábamos en el apartado anterior. La mayoría de los paneles rupestres que han sido cristianizados con estos mitos, son relativos a escenas de la vida cotidiana de la Virgen, concretamente con acciones relacionadas con su aseo y peinado. Junto al santuario de Cadeiras, en Sober, existe catalogada una referencia denominada Pedra da Virxe (GA27059REF004), donde se hallaban un número indeterminado de cazoletas. Actualmente la piedra ha sido fracturada con la consiguiente desaparición de los grabados. Según la leyenda la Virgen surgió de esa piedra, y posteriormente usó las pilas para lavarse y peinarse. Como consecuencia de esta aparición se construye el santuario a pocos metros del afloramiento. Otro panel denominado Pena da Virxe, en Pantón, posee una treintena de cazoletas dispuestas junto a una pila natural, con una leyenda similar a la anterior.

El segundo tipo de leyendas se distribuye, al igual que las religiosas, por toda la geografía gallega, con el nombre de lendas dos mouros. Son de carácter pagano y pretenden explicar de un modo fantástico la existencia de los castros y de los petroglifos. En los castros residian los mouros, seres del imaginario popular que poseían grandes riquezas de oro. Sus tesoros eran escondidos bajo piedras grabadas y huecas

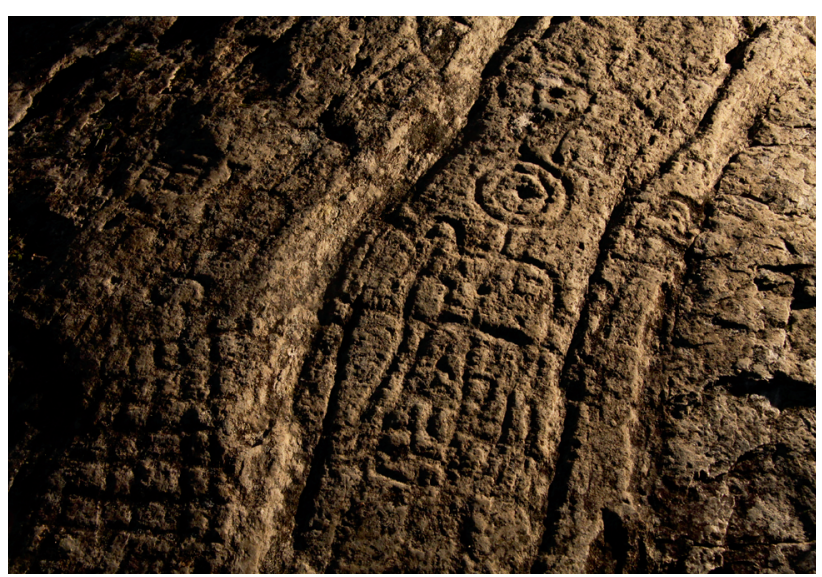

ム Figura 12. Detalle del Petroglio do Regueiro/Tapado do Monte, Anllo, Sober. 


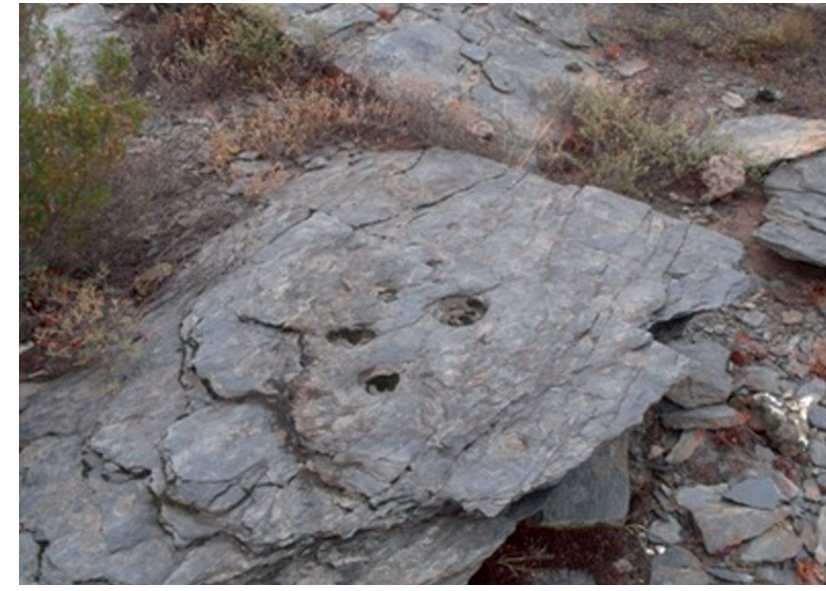

A Figura 13. Petroglifo de Fiais, Cereixido, Quiroga. El carácter laminar del soporte afecta a su conservación.

para diferenciarlas de las restantes. Son estas últimas nuestros petroglifos, que según el mito "si pisaban fuerte sobre ellos sonaba hueco por dentro".

Las huellas dejadas en el paisaje por nuestros antepasados han favorecido el enriquecimiento de nuestra tradición oral, en forma de leyenda o de cuento de mouros, que incluso hoy en día nos aportan claves para encontrar nuevas estaciones aún sin catalogar.

\subsection{Cronología}

La mayoría de las investigaciones centradas en los grabados rupestres gallegos, desarrolladas a lo largo del siglo pasado, centraban su atención en la cronología de las estaciones. Pues la datación ha sido y es uno de los problemas principales a los que se han enfrentado los numerosos investigadores de la materia. A partir de finales de los años 70 se vinculan directamente a la Edad de Bronce, teoría defendida por un gran número de especialistas. Actualmente la mayoría de los estudios afirman que el período de mayor apogeo de la cultura rupestre al aire libre se encuentra en la transición entre el III-II milenio antes de nuestra era. Es decir, a finales del megalitismo y durante el desarrollo inicial de la metalurgia. En esta etapa el desarrollo social, tecnológico y económico crea un clima propicio para el desarrollo de este "arte". Será en esta época cuando comiencen los primeros contactos entre las comunidades atlánticas, de ahí los paralelismos presentes en estas culturas. Autores foráneos datan los grabados rupestres escoceses en torno al año 3200 a.C., mientras que los diseños circulares entre el 2000-1500 a.C. (Brigantium VIII 1993-94: 268).

Autores como Vázquez Varela vincula los símbolos funerarios megalíticos hallados dentro de los dólmenes, concretamente en sus ortostatos, con las representaciones en rocas graníticas al aire libre, por lo que deduce que estas últimas pertenecen al Calcolítico o Edad de Cobre, que se desarro-

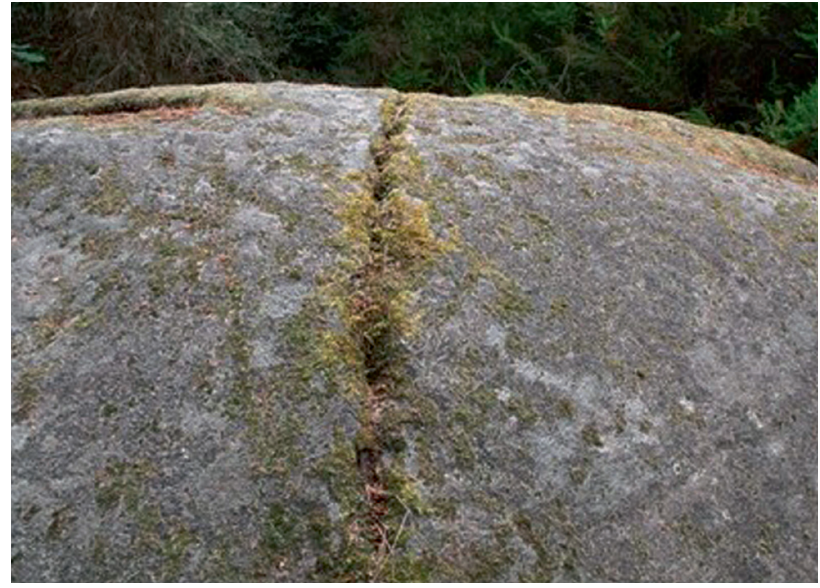

A Figura 14. Petroglifo dos Cótaros ou dos Toxaes, Figueiroá, Sober. El panel conserva marcas de cuña realizadas por un cantero local.

Ilará hasta el Bronce Medio, y algunas incluso hasta la Edad de Hierro. Además crea los términos cronología relativa y cronología absoluta. La primera claramente relacionada con las diversas suposiciones a lo largo de la historia, de la que no poseemos datos que verifiquen la absoluta certeza, basándonos en métodos de sincronismo o superposición de elementos en las superficies. Por el contrario la representación de armas es la única representación que podemos datar sin temor a errar en la Edad del Bronce, basándonos en el tipo de útil (Bronce Inicial, Medio y Final) (Vázquez Varela 1993: 118-123).

El castro de Santa Tegra es destacado en numerosos estudios por la ubicación de un soporte granítico con grabados rupestres en su entorno, a dicha piedra se ha superpuesto una construcción castrexa, lo que confirma la antigüedad de los petroglifos respecto a la cultura de los castros.

Tras lo expuesto anteriormente mantenemos el período Calcolítico y Edad de Bronce para enmarcar la adscripción cultural de los grabados del sur de Lugo, vinculados desde su aparición con sus antepasados neolíticos, donde perduraron sus estilos a la hora de reproducir los motivos, que tras su período de auge Calcolítico, pierden intensidad a la vez que se aproximan a la Edad de Hierro.

Por otro lado las señales de término, tableros de juego y cruces se encuentran datadas todas ellas en época histórica, concretamente medieval, quedando al margen del estudio prehistórico. Aún así, se han mencionado por las vinculaciones directas que poseen con los grabados analizados.

\subsection{Conservación}

Un aspecto imprescindible a la hora de realizar un estudio arqueológico es verificar el estado del yacimiento a analizar. En este apartado repasaremos la situación actual de los grabados mediante dos aspectos principales: las causas de las alteraciones y el grado de las mismas. 
Las causas de las alteraciones son producidas principalmente por agentes denominados naturales y antrópicos, que propician el deterioro de los paneles. Los primeros son quizás los más preocupantes, puesto que no está en nuestra mano su control.

Los agentes característicos de nuestro ecosistema interactúan con las rocas por hallarse expuestas a ellos, principalmente son: Iluvia, humedad ambiental, temperatura, viento, luz, gases ( $\mathrm{CO}^{2}, \mathrm{O}^{2}$, etc.) y sus interrelaciones. La climatología gallega condiciona el carácter de los procesos de alteración (meteorización) de origen químico. Concretamente la hidrólisis y la disolución de algunos de sus minerales, feldespatos y micas, parecen ser el origen de la forma más frecuente de alteración de los petroglifos gallegos. Estos producen una generalizada pérdida de material que redondea sus formas y reduce el surco, pero de desarrollo atenuado, que permite una aceptable conservación de los grabados hasta nuestros días.

Los procesos de abrasión directa por el agua y el viento no parecen tener una influencia muy acusada. Siempre matizando en el tipo de piedra y el microclima en el que se emplace.

Otras alteraciones naturales son producidas por organismos vivos característicos del ecosistema: los organismos, concretamente los líquenes, son un incesante degradante y el principal agente de alteración natural para los petroglifos gallegos, donde casi la totalidad de las rocas analizadas presentan este microorganismo.

Hallamos en las alteraciones una doble acción mecánica: penetración de rizoides y la contracción-expansión de talos, junto a tres acciones químicas: retención de aguas, secreción de compuestos químicos y la producción de gases.

Las acciones antrópicas son otro factor de riesgo, donde las extracciones de piedra han sido sin duda las más dañinas. Estas sustracciones formaban parte de sistemas económicos tradicionales, que actualmente se encuentran en proceso de desaparición. Además, las canteras existentes son reguladas por la legislación patrimonial. Sin embargo, las acciones pasadas han eliminado parcial o totalmente numerosos grabados rupestres. Concretamente, el Petroglifo dos Cótaros, en Sober, de gran importancia por la variedad y calidad de sus grabados, muestra diversas marcas de cuña para la extracción de piedra por parte de los canteros locales.

Cabe señalar, también, las obras e infraestructuras realizadas en el ámbito rural, de difícil control, la repoblación forestal, los incendios y el vandalismo son otros de los agentes antrópicos que alteran la conservación de nuestro patrimonio rupestre.

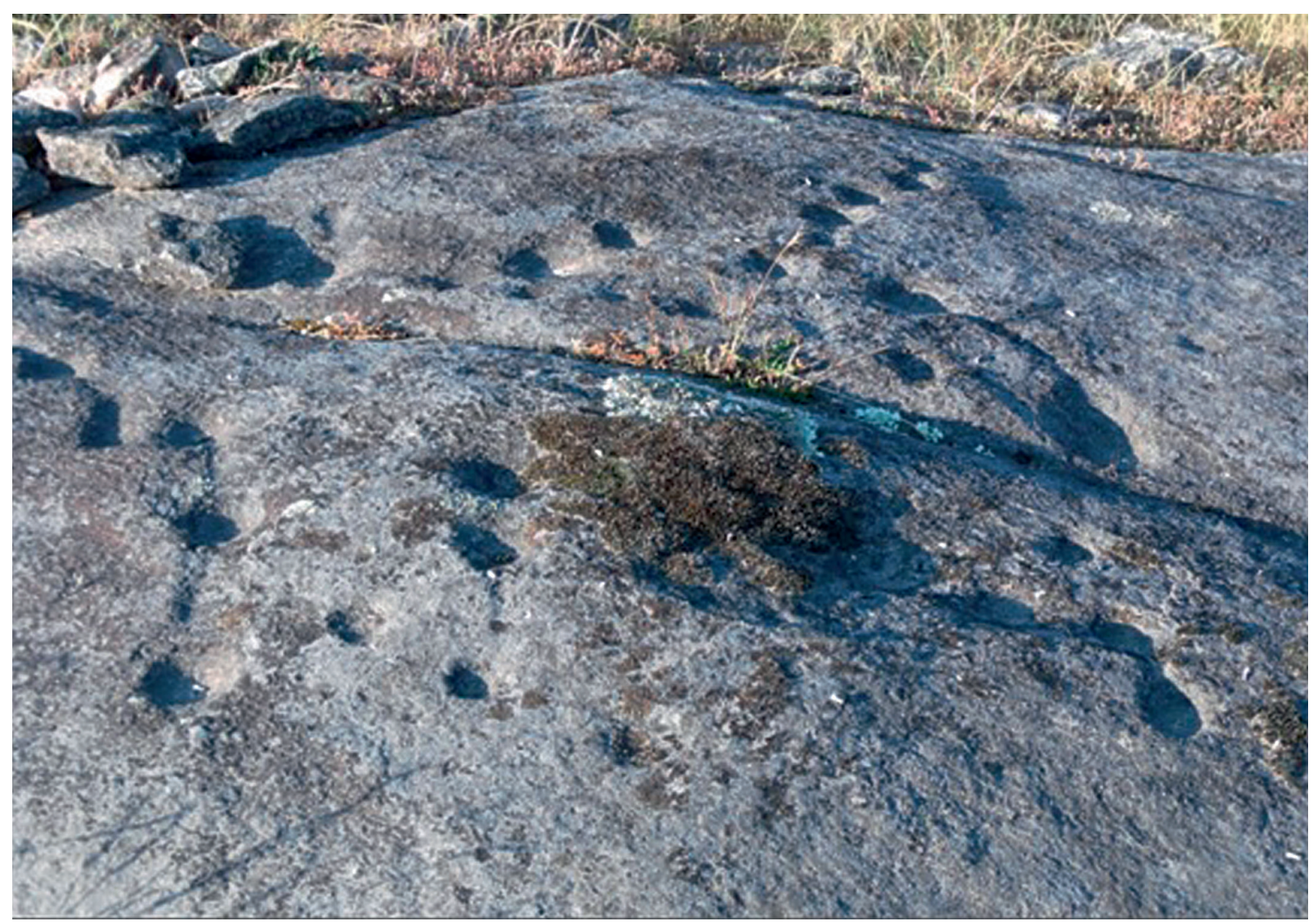

A Figura 15. Cazoletas del Petroglifo do Barcal, Pinol, Sober. 
Por ello, es necesaria la existencia de medidas preventivas y estudios científicos, que junto a los estudios clásicos de catalogación y documentación de los aspectos arqueológicos de las estaciones, amplien los datos a informaciones sobre las alteraciones y riesgos específicos de cada emplazamiento, siempre de la mano de expertos en la materia. Como nota final mencionar que la mayoría de las estaciones se encuentran catalogadas por la Delegación de Patrimonio de la Consellería de Cultura y Turismo de la Xunta de Galicia, pero solamente los petroglifos de Cótaros y Tapado do Monte presentan indicadores que señalen su presencia, pero anulado en la primera estación por la abundante maleza que la rodea. Sólo Tapado do Monte posee un panel explicativo con información general de este tipo de representaciones. Por este motivo reivindicamos una revalorización del patrimonio rupestre, desconocido y poco valorado, para que sea protegido antes de su desaparición.

\subsection{Conclusiones}

El estado actual de la investigación en torno al fenómeno del arte rupestre gallego está en pleno auge, prueba de ello es el número de publicaciones existentes desde finales del siglo pasado y principios del XXI. Sin embargo, los trabajos lucenses se encuentran en clara desventaja si los comparamos con la provincia pontevedresa. El presente trabajo ha sido el único realizado sobre las tres comarcas del sur de Lugo, lo que define claramente la situación. Con la catalogación de todas las estaciones de la zona sur se pueden observar el grado de calidad y cantidad de los grabados, de mayor modestia que los estudiados en la zona del río Lérez, pero que demuestran la existencia de sociedades que ocupaban el interior del territorio galaico en el período Calcolítico.

Con el avance del trabajo de campo han salido a la luz nuevas estaciones, recogidas con una doble intencionalidad: actualizar los listados de Patrimonio e insistir en la existencia de más grabados por descubrir. En concreto, en el ayuntamiento de Pantón, hasta hace menos de una década no se conocía la presencia de ningún panel rupestre. Hoy en día posee una veintena de grabados, once de ellos sin catalogar por la Delegación de Patrimonio de la Consellería de Cultura e Turismo, e incluidos en nuestro estudio. Sucede lo mismo en Sober, donde se han incluido nueve paneles inéditos.

Además de agregar nuevas estaciones, ampliamos la diversidad de soportes en los que se realizan los grabados, refutando así a autores como De la Peña, que señalaban el granito como único material sobre el cual se realizaban las representaciones. Tras analizar en Quiroga dos soportes de pizarra y en Monforte ocho de esquisto, comprobamos que, al igual que ocurre en la actualidad, utilizaban el material de su entorno más cercano. Por lo tanto, dotan de relevancia el emplazamiento de la roca y no su composición.

La catalogación se compone de cincuenta fichas donde se expone una simple aproximación de la situación actual de los grabados; por consiguiente, es necesario, de cara a un futuro próximo y como ampliación a este tema, realizar un estudio más exhaustivo de la zona sur lucense, centrándose en áreas determinadas, con aportaciones topográficas (laser, escáner, 3D), reproducciones digitales, mayor repertorio fotográfico, descripciones pormenorizadas de cada motivo, un análisis técnico, etc. •

\section{BIBLIOGRAFÍA}

Acuña Castroviejo, F. 1980: "A Prehistoria e a Idade Antiga". En W.AA.: Historia de Galicia, I. Editorial Cupsa y Editorial Planeta. Barcelona: 33-54.

AmeiXeIRAS SÁnChez, F., ARCA CALdAS, 0. 2002: "A arte rupestre". Tapa 29:39-48. AnAtI, E. 1968: Arte rupestre nelle regioni occidentali della Peninsola Iberica. Ed. del Centro. Brescia.

Álvarez Núñez, A., Velasco Souto, C. 1979: "Nuevas insculturas en Campo Lameiro". Gallaecia V: 17-61.

Barros Sivelo, R. 1875: Antigüedades en Galicia. A Coruña.

BouzA BREY, F. 1943: "Grabados rupestres serpentiformes de tierras de Lugo", Boletín de la Comisión de Monumentos Históricos y artísticos de Lugo l: 134-138.

Bóveda Fernández, M. J., Cañizo Fraga, J. A., Vilaseco Vázquez, J. I. 1999 "Lugares para gravar, lugares para morrer. Petroglifos e cistas na Idade do Bronce no noroeste da Península Ibérica". Gallaecia XVIII: 89-102.

BradLEY, R., Fábregas Valcarce, R. 1996: "Petroglifos gallegos y arte esquemático. Una propuesta de trabajo". Complutum Extra 6(II): 103-110.

Carré Alvarellos, L. 1949: "Piedra con inculturas en Espasante", Boletín de la Comisión de Monumentos Históricos y artísticos de Lugo III: 283-289.
Carrera Martinez, F., Costas Goberna, F.J., Peña Santos, de la A. 2002: Grabados rupestres en Galicia. Caracteristicas generales y problemática de su gestión y conservación. Diputación Provincial de Pontevedra. Pontevedra.

Clottes, J., LeWIS Williams, D. 2001: Los chamanes de la Prehistoria. Ed. Ariel. Barcelona.

Costas Goberna, F. J. 1999: Arte rupestre no sur da Ría de Vigo. Instituto de Estudios Vigueses. Vigo.

Costas Goberna, F. J., Nóvoa Álvarez, P. 1993: Monografias. Los grabados rupestres de Galicia 6. Museo Arqueolóxico e Histórico. A Coruña.

Costas Goberna, F. J., Nóvoa Álvarez, P., Albo Moran, J. M.a 1993-1994: "Los grabados rupestres de Pena de Chaos y Pena da Moura en San Fiz de Amarante (Antas de Ulla, Lugo)". En Brigantium 8: 263-273.

Costas Goberna y F. J., Hidalgo CuñarRo, J. M. (coord.) 1996: Los motivos geométricos en los grabados rupestres prehistóricos del continente europeo. Asociación de Arqueología Viguesa. Vigo.

- 1997: Los motivos de fauna y armas en los grabados prehistóricos del continente europeo. Asociación de Arqueología Viguesa. Vigo.

- (Eds.) 1998: Reflexiones sobre el arte rupestre prehistórico de Galicia. Asociación de Arqueología Viguesa. Vigo.

Fábregas ValCARCE, R. 2005: Descuberta de gravados rupestres na comarca do Deza: avance preliminar". En Descubrindo: Anuario de estudios e investigación de Deza 7: 253-270. 
- et alli 2008: "Aportacións ó estudio da prehistoria da cunca media do Miño. Os asentamentos en cova e ó aire libre". En Gallaecia 27: 63-88.

- 2009a: "Representaciones de armas no interior de Galicia (Comarca do Deza, Pontevedra): Unha reflexión sobre a distribución e cronoloxía destes motivos". En Gallaecia 28: 49-68.

- 2009b: "A Context for the Galician Rock Art". En Rodrigo de Balbín Behrmann (ed.): Grabados rupestres de la fachada atlántica europea y africana. 0xford: 69-83.

FERNÁNDEZ PINTOS, J. 1989: "La cronología del arte rupestre gallego. Estado actual de nuestros conocimientos". En Actas do $1^{\circ}$ Congreso Gallaecia. Deputación Provincial de Pontevedra. Pontevedra: 221-233.

Ferro Couselo, X. 1952: Los petroglifos de término y las insculturas rupestres de Galicia. Tesis doctoral. Universidade de Santiago de Compostela.

Filgueiras Rey, A. I., Rodrígues Fernández, T. 1994: "Túmulos y Petroglifos. La construcción de un espacio funerario. Aproximación a sus implicaciones simbólicas. Estudio en la Galicia Centro-Oriental: Samos y Sarria". Espacio, Tiempo y Forma. Serie I. Prehistoria y Arqueología 7: 211-253.

Garcia Martínez, M. C. 1969-1970: "Sobre la tipología de los grabados rupestres lucenses". Boletín de la Comisión de Monumentos Históricos y artísticos de Lugo VIII: 250-259.

Gil Agra, M. a D., Concheiro Coello, A. 1993-1994: "A estación de grabados rupestres ao aire libre de Braña das Pozas (Porto do Son, A Coruña)". Minius II-III: 7-15.

GonzÁlez Reboredo, X. M. 1976: "Petroglifos da provincia de Lugo". Boletín Auriense VI: 57-66.

- 1969: "Estación de arte rupestre do Incio". Cuaderno de Estudios Gallegos XXIV: 7-14.

López Cuevillas, F., Bouza-Brey, F. 1929: Os Oestrimnios, os Saefes e a ofiolatría en Galicia. Nos. A Coruña: 27-194.

Peña SANTOS, A. DE la 1998: "Os gravados rupestres galaicos". En Fábregas Valcarce, R., Carballo Arceo, L. X., Acuña Catroviejo, F. (coord.): Prehistoria; Arte castrexa; Arte da romanización. Promocións Culturais Galegas. Vigo: 65-80.

- 1978: El arte rupestre gallego al aire libre: estado actual del problema y modelo para su estudio por áreas geográficas naturales: la Península del Morrazo, Pontevedra. Tesis doctoral. Universidad de Santiago de Compostela.

- 1979: "Petroglifos gallegos: grabados rupestres prehistóricos al aire libre en Galicia". Ed. Castro. Sada.

- 1984: "Petroglifos". En W.AA.: Gran Enciclopedia Gallega XXIV. Santiago de Compostela: 227-230.

- 1999: Os petroglifos galegos. A Nosa Terra. Vigo.
- 2003: Galicia. Prehistoria, castrexo e primeira romanización. A Nosa Terra. Vigo.

Peña Santos, A. de la, Rey García, J. M. 2001: Petroglifos de Galicia. Via Lactea. A Coruña.

Pérez Alberti, A. (dir.) 1993a: "Xeomorfoloxía". En Xeografía de Galicia 3. Gran Enciclopedia Galega Edicións. Santiago de Compostela: 37-46.

- 1993b: "A Poboación e a Acción Xeodemográfica". En Xeografía de Galicia 4. Gran Enciclopedia Galega Edicións. Santiago de Compostela: $30-37$.

RIEGA, L. 1892: El río Lérez. Pontevedra.

Rodriguez GonzÁlez, R. (coord.) 2005a: "Os Ancares e o Courel". En Galicia en Comarcas 2. Ir Indo Edicións. Vigo.

- 2005b: "Chantada e A Ulloa". En Galicia en Comarcas 7. Ir Indo Edicións. Vigo.

- 2005c: "Lemos e Sarria". En Galicia en Comarcas 13. Ir Indo Edicións. Vigo.

Rodriguez Rellán, C. et alli 2008: "O Conxunto de petroglifos de Campo da Uz (Santa María de Areas, Chantada) e as súas vías de tránsito cara o interior lucense". En Gallaecia 27: 35-61.

SANTOS Estévez, M. 1999: "Arte rupestre e construcción dos territorios na Idade do Bronce en Galicia. En Gallaecia 18: 103-118.

Sobrino BuHIJAS, R. 1935: Corpus Petroglyphorum Gallaeciae. Compostellae: Seminario de Estudios Gallegos. Santiago de Compostela.

Vázouez SeiJAs, M. 1945: "Aportación de la provincia de Lugo al "Corpus Petroglyphorum Gallaeciae". En Boletín de la Comisión de Monumentos Históricos y artísticos de Lugo II: 75-81.

VÁzouez VArela, J. M. 1995: "Gliptografía y petroglifos prehistóricos en Galicia". En Actas das Xornadas Internacionais de Gliptografía. Concello de Noia. Noia: 77-85.

- 1993a: "Megalitismo". En Galicia Arte IX. Hércules de Ediciones. Santiago de Compostela: 26-72.

- 1993b: "Calcolítico". En Galicia Arte IX. Hércules de Ediciones. Santiago de Compostela: 74-85.

- 1993c: "A Idade do Bronce". En Galicia Arte IX. Hércules de Ediciones. Santiago de Compostela: 98-105.

- 1993d: "Os petroglifos" En Galicia Arte IX. Hércules de Ediciones. Santiago de Compostela: 106-157.

Villoch VÁzouez, V. 1995a: "Análisis de emplazamiento tumular en Galicia: el caso de la necrópolis de Saídos das Rozas (Campolameiro, Pontevedra)". En Actas del XXII Congreso Nacional de Arqueología (Vigo 1993). Vigo: 373-378.

- 1995b: "Monumentos y petroglifos: la construcción del espacio en las sociedades constructoras de túmulos del Noroeste peninsular". En Trabajos de Prehistoria 52: 39-55. 